\title{
5 \\ How do you measure a social impairment?
}

\section{Disrupting the welfare state's 'bonds of love'}

If the Children Act 1948 and the publication in 1955 of the Underwood Report of the Committee on Maladjusted Children were significant moments in the formation of government policy towards children based on the Tavistock Model of Human Relationships, then the Mental Health Act 1959, the 1970 Local Authority Social Service Act, and the Education (Handicapped Children) Act 1970 were the key pieces of legislation that would begin to topple the Tavistock hegemony. These Acts helped to build new models for understanding children's rights to relationships and new models of social welfare that challenged the ideology of organising child welfare services with the aim of preventing child 'maladjustment'. New models of child development built around the new autism concept would increasingly be used to present alternatives to this social model and to develop a new model of child development and the formation of relationships in children that supported new government policies aimed at correcting individual impairments rather than imposing an idealistic model of family life that would prevent the frustration of instincts and the resulting 'maladjustment' of children.

The closure of deficiency institutions and asylums following the Mental Health Act 1959 was putting increasing pressure on the government to develop welfare and social work provisions that would enable the care of these individuals in new residences other than in large-scale institutions. In the mid-1960s, the need for robust structures to support social work services was highlighted after various committees of enquiry had put the needs of unique social groups under the spotlight, in particular the 'mentally handicapped'. These committees drew attention to 
the fact that social services within a welfare state required advocates and mediators who would work in the interests of their patrons, rather than imposing a top-down system of welfare. In 1965, the well-known social researcher, Richard Titmuss, pointed out that many people with mental health problems or other isolating conditions would not be able to rely on a 'family department' to cater to their problems, and argued that social services should be organised around the facilities to be offered, rather than around fragmented categories of those in need. ${ }^{1}$ In the same year, the Seebohm Committee was established to review the organisation of social services in order to ascertain what changes were needed to ensure an effective family service now that large-scale institutional care no longer served a purpose in maintaining social stability. ${ }^{2}$

When the Seebohm Committee reported on Local Authority and Allied Services in 1968, they recommended that local authority social services departments be established and that appointed Directors of Social Services should manage these departments. Within these plans, it was argued that children with mental health problems should be managed via these departments rather than health departments. ${ }^{3}$ This new managerial framework would replace specialist services, such as psychiatric social work, and create a new overarching general framework. In Scotland, comprehensive changes were already being implemented via the Social Work (Scotland) Act 1968. On 29 November 1969, the Association of Psychiatric Social Workers and the Association of Mental Welfare Officers were both officially terminated. The Seebohm Committee had deliberated at length on the question of whether or not mental health services should become the responsibility of health departments or whether they should be integrated into the new social services departments. In the end, they opted for the latter, arguing that failure to acknowledge mental health as a social problem 'would mean further segregation of the mentally disordered when in fact the community is becoming ready for their integration.' The Conservative government implemented the Local Authority Social Service Act 1970 soon after they came to power under Edward Heath, following Seebohm's proposals. Social service departments were established in all local authorities in Britain and the Central Council for Education and Training in Social Work (CCETSW) was established, launching the generic Certificate of Qualification in Social Work in 1972. Seebohm had proposed the 
creation of local social service departments with an optimism about the way these would work to 'enable the greatest number of individuals to act reciprocally'. The belief was that these would provide a 'community based and family oriented service' that intervened early at a local level. He had argued that field-level social workers should be skilled in dealing with a range of needs, rather than in any specialist area. The reforms forged a sense of 'society' that social workers were trained to alter and manipulate at a local level. Social work agencies thereafter took over much decision-making and service organisation for children who would have previously been dealt with by health authorities. This moved the study and diagnosis of children's psychological states into a much wider nexus of application.

One area in which social workers cam to directly impact children's lives was via the 'care order'. After 1969, there were only two ways in which a child could be committed into care of the state. Either they could be received into care under Section 1 of the Children Act 1948, or they could be taken into care under the Children and Young Persons Act 1969, a central piece of legislation in relation to juvenile justice that aimed to shift responsibility for young offenders from the police, magistrates and prisons onto local authorities, social workers and the Department of Health. ${ }^{5}$ Unless criminality was involved, the care order became the central bureaucratic tool employed to take children out of the care of their parents. ${ }^{6}$ Local authority social workers were the typical agency to issue care proceedings, in which they had to prove that the 'child's proper development is being avoidably prevented or neglected or his health is being avoidably neglected or he is being ill treated', or that he was exposed to 'moral danger', 'beyond the control of his parents', guilty of an offence or not receiving education suitable to his 'age, ability and aptitude.' This increased the power of social workers and educational authorities in the classification and psychological assessment of all children. More importantly, it shifted the nexus of power for the committal of children fully away from the assessment of their intelligence or social inefficiency and towards a more detailed assessment of their psychological and physical development. This placed a large amount of power in the hands of social workers, power that would come to be increasingly challenged over the following decades. 
It is not a coincidence that it was in this climate of radical change in the organisation of social services that autism was first officially recognised in British law. It was the Chronically Sick and Disabled Persons Act 1970 that first enshrined the category of autism in law by listing it as a disability that assured special education, along with 'other forms of early childhood psychosis.' ${ }^{8}$ This was a direct response to the evidence submitted by John and Lorna Wing on behalf of SAC and a clear indication that the government was beginning to rethink the education and long-term social integration of previously excluded groups. The Act guaranteed that professional organisations paid attention to children categorised with autism and psychosis and ensured that their families were informed about their rights to education, child welfare provisions and other social work services. It also entitled them to forms of financial assistance for people registered with disabilities. The National Insurance Act 1970 saw the introduction of an attendance allowance to be paid when a severely mentally or physically ill person was being cared for within the home. ${ }^{9}$ The National Insurance Act 1971 and the Social Security Act 1975 introduced invalidity benefits and the noncontributory invalidity pension respectively. ${ }^{10}$ In 1976 , the Department of Health and Social Security (DHSS) also introduced mobility allowances. ${ }^{11}$ Individuals with autism could potentially claim all of these benefits if their carers could demonstrate that they were sufficiently impaired to require them. Such benefits provided additional support for the care of these children whose full-time institutional care was no longer supported through the hospital system.

Psychological research by Tizard, O'Connor, Rutter and other new autism psychologists was demonstrating the specific problems with sense perception and conceptualisation that autistic and 'subnormal' children were thought to suffer from, thereby increasing the possibility that teaching techniques could be developed to compensate for these impairments. This encouraged not only SAC, but also other charitable groups to campaign for the government to rethink their policy on keeping 'subnormal' children in hospitals rather than schools. This put pressure on the government to rethink the education of all children, no matter what their problems or impairments, as it was becoming increasingly difficult to argue that certain subsections of the population were completely 'ineducable' and needed to be retained in hospital for the sake of wider social needs. One month 
after the Chronically Sick and Disabled Persons Act was passed, Lawrence Pavitt, MP for Willesden West, tabled a motion in the House of Commons for changes to the Education Act 1944, requesting that 'autistic' children be included in the eleven categories previously listed as requiring special education. Drawing attention to new diagnostic testing methods, he pointed out that, although the issue of autism was 'comparatively small, in proportion' to all mental handicap, it was 'indicative of a wider problem relating to new and sophisticated diagnostic techniques. ${ }^{12}$ Highlighting the work of the new autism psychologists, he argued that the study and treatment of autism was the first step towards the study and treatment of all forms of 'mental handicap', and that the government needed to take a stronger stance on the education of autistic children, as well as their integration into the wider community once they turned sixteen. ${ }^{13}$

These sentiments slotted neatly into the reshuffles that followed Seebohm's proposals and that would transform the social welfare system to make it more integrated and to enable growing sections of society to access it. In 1965, the first independent school solely for 'autistic' children was founded by the Society for Autistic Children, shortly followed by two more schools. By the late 1960s, there were also many schools specifically for children with 'severe language disorders. ${ }^{14}$ In 1968, the Association for All Speech Impaired Children (AFASIC) was established in London, a reflection of these changes. ${ }^{15}$ Pressure was also coming from groups founded to represent all 'ineducable' children. The growth in specialist schools for 'autistic' and 'language impaired' children put even more pressure on the government to revise their position concerning the 'ineducability' of 'subnormal' children. The creation of 'social services' had a huge impact on many children's lives July 1970, the government announced that it intended to transfer responsibility for the education of all 'severely subnormal' children from the Department of Health to the Department of Education and Science (DES). At the same time, special educational services would have to expand to manage these new groups. This new administrative plan was written into the Education (Handicapped Children) Bill, which received Royal Assent in July 1970, just one month after the Conservative government came to power.

The transfer of functions from the Ministry of Health to the DES directly affected 32,837 children. Of these, 7,711 were registered as 
subnormal and were resident in hospital, whilst the other 25,126 were attending Junior Training Centres or Special Care Units. An additional 1,340 children were attending independent establishments such as the Autistic Society schools. ${ }^{16}$ Because the Education Act 1944 compelled local education authorities (LEAs) to ascertain which 'educable' children required specialist education, the DES had collected figures on the exact numbers of children ascertained under each category defined in the Act. Between 1960 and 1970, there had been a steady rise in the number of children defined as both 'maladjusted' and 'educationally subnormal' attending specialist schools as a direct result of the Mental Health Act 1959. In 1960, 1,742 children were classified as 'maladjusted' and 32,815 were classed as 'educationally subnormal'. In 1970, this figure had risen to 6,293 and 51,768 respectively. ${ }^{17}$ Over the same period, the numbers of adults and children in hospital for 'subnormality' had reduced by $33,875 .{ }^{18}$ However, after 1970 , many of these children would begin to be reclassified.

After 1970, the five categories of children whose numbers rose significantly were the 'maladjusted', the 'physically handicapped', 'epileptics', those with a 'speech defect' and the 'educationally subnormal'. Between 1970 and 1975, the number of 'maladjusted' children registered at the DES increased from 6,293 to 13,527, the number of physically handicapped pupils increased from 8,830 to a total of 12,224 , the number of epileptic children rose from 1,015 to 2,205 and the number of children with a 'speech defect' increased almost tenfold from 828 to 6,893 . The number of 'educationally subnormal' children shot up from 51,768 to 72,636 , of whom 19,892 were assigned the new category of 'severely educationally subnormal'. In addition, 542 children were registered under the new category 'autistic.' ${ }^{19}$ In total, this showed an increase of 39,293 newly categorised children, a number comparable with the 34,177 who were transferred from the health authority to the DES and then integrated into the education system through various classificatory routes after 1970 . The small discrepancy in figures can be accounted for by population increases, the growth of specialist education services generally and the elimination of the category 'delicate', which had previously classified 1,729 children. ${ }^{20}$ It is clear from these figures that when 'subnormal' or 'defective' children were integrated into the general education system, they entered along many different routes and in doing so assumed many different classifications, such as 
'speech disorder', 'maladjusted' and 'autistic'. There were many increases in numbers of children with particular diagnoses. However, at this time, the 'autistic' label was still only applied to a minority of children.

After 1970, there was also an increase in the number of children with 'psychosis' and 'autism' diagnoses attending special schools and special classes that had not traditionally been created for 'autistic' children. The reason for this was the final closure of schools for all children with subnormality that led to the need for additional specialist schooling facilities. Many children diagnosed with 'autism', 'schizophrenia' and 'psychosis' diagnoses were sent to language units, such as that attached to the Forest Oak special school in Solihull, ${ }^{21}$ or the Charles Burns Unit for children with language and communication problems in Warwickshire. ${ }^{22}$ Other children were sent to mixed special schools such as Court Meadow special school in Sussex, ${ }^{23}$ the Dysart Special School in Surrey ${ }^{24}$ or the J. F. Kennedy Special School in Newham. ${ }^{25}$ Some children were sent to Steiner schools, as in the 1950s, and many of these reclassified themselves as schools for children with 'severe learning difficulties', such as Sunfield School in Worcestershire. ${ }^{26}$ Each of these schools had its own approach to the education of children and each claimed to specialise in a particular type of child. Following their lead, some special schools, such as Doucecroft School in Essex, were classified as schools specifically 'for autistic children. ${ }^{27}$ In the late 1960s, Rutter and Lawrence Bartak had conducted studies of the best kind of educational setting for children diagnosed with autism using funding from the DES and the Gulbenkian foundation. ${ }^{28}$ They drew attention to the fact that although psychoanalysts and behaviourists presented radically different theories, educational approaches were often quite similar in practice. Most importantly, they all encouraged social engagement. They argued that the most effective approach was when the 'perceptual, motor and cognitive handicaps of the children were seen as primary and around which education was to proceed. ${ }^{29}$ Organising structured activities for an autistic child was thus the best way to increase his behavioural repertoire' and to facilitate more successful adaption to his environment. As Rutter described it, 'as social demands were increased, so was the likelihood that the child would make some kind of social response; as the task-related features increased, so did the rates of productive behaviour. ${ }^{30}$ Because the definition of 'autism' had been given support via epidemiological studies, the justification for treatment 
approaches based on a new model of 'socialisation' and training followed, but these recommendations did not tend to be particularly specific, focusing on general social engagement. This is perhaps understandable given that more children were being integrated into society.

Although the category of autism was used to classify only a few children in 1970, its appeal would gradually expand as children's psychiatric needs were increasingly recognised in an educational setting. In the mid-1970s, SAC urged parents to get early diagnoses for their children if they suspected they had autism. This was encouraged for children 'as a way of triggering a whole range of activities on their behalf from advice to parents in the management of their children to directing them towards appropriate specialised care and education. ${ }^{31}$ A diagnosis of 'autism' ensured that a child received greater attention and also had the weight of the Society for Autistic Children behind it. By the 1970s, it was therefore becoming a somewhat desirable label, and definitely preferable to 'subnormal.'.

It is within this new social and legal climate that psychiatric epidemiology would thrive as a social scientific methodology that could be used by government departments in order to plan the management of social service departments. Bowlby and Winnicott's work on the need for family security and mother love was gradually pushed aside to make room for new models of psychological development that did not overlook the needs of 'subnormal' populations and which recognised that social services had to cater to populations with very distinct individual needs. The work of Lotter, Tizard, Rutter and many of the new generation of psychiatric epidemiologists and statistical researchers was important in guiding discussions regarding the future of hospital and social services because it claimed to provide an accurate measure for all social needs. As Albert Kushlik put it, 'the epidemiological approach lends itself to the development of a service which can both anticipate and deal with problems which are known to be present a long time before they come to the notice of existing services. ${ }^{33}$

The rest of this chapter explores how new techniques were developed to measure 'social impairment' in children in light of the Seebohm reforms of 1968 and other legal changes of the early 1970s. These led to major changes in the organisation of educational and social services. For example, the Local Authority Social Service Act 1970 led to the establishment of social service departments in each locality. Whereas 
previously, different welfare departments had been managed separately, the 1970 Act led to the foundation of 'social services', designed to facilitate social functioning for all. This helped to consolidate the idea that autism was a measurable and quantifiable entity, and that it was a kind of 'social impairment'. Attempts to investigate and understand autism then came from diverse fields of research. The social sciences, in particular, offered innovative kinds of analysis and conceptualisation of autism, helping to enliven the concept and form it into its current incarnation.

The development of educational psychology and the Summerfield Report

In order to cope with the huge impact that the integration of mental defectives was having on the schools system, and to plan a psychological strategy, in 1968, at the request of the Secretary of State for Education and Science, the president of the British Psychological Society (BPS), Arthur Summerfield, published a report on the number of educational psychologists that should be employed in British schools. The Summerfield Committee argued that education authorities were the most appropriate bodies to appoint psychologists to work with children and that psychological work should be organised in the field of education 'on a much larger scale than at present', as this 'would be conducive to a high standard of service, to efficiency, and to economy of manpower. ${ }^{34}$ The report recommended that one educational psychologist per 10,000 schoolchildren should be employed and that new training should be implemented. ${ }^{35}$ A BPS committee was quickly established to draft a syllabus for a BPS Diploma in Educational and Child Psychology and consultations began with the Division of Educational and Child Psychology and the Association of Education Psychologists. ${ }^{36} \mathrm{It}$ was agreed that the syllabus would teach candidates 'a critical knowledge of biological, neurological, sociological factors affecting development', including 'the significance of early learning' and 'critical and sensitive periods of development'. As well as theories on intelligence, students would study theories of cognitive development, including the work of Piaget, and 'the major theories of personality development including psychoanalysis, ethology and learning theory’. With regard 
to experimental and statistical psychology, candidates would examine the 'assessment of sensory, motor and perceptual handicaps' as well as 'survey methods and epidemiological studies'. Candidates also had to develop a good knowledge of 'exceptional children', including 'handicapped children'. In addition to the eleven labels of 'handicap' drawn up in 1945, the BPS now included 'children with specific learning disabilities' and 'psychotic children., ${ }^{37}$

It was via the development of training courses for educational psychologists following the Summerfield Report that the study of 'psychotic' children became part of everyday practice. The BPS committee argued that trainee developmental and educational psychologists should make direct contact with 'a wide range of children and adolescents', including the 'psychotic' and 'those with intellectual, sensory and physical handicaps'. It was no longer possible for psychological professionals to sideline children who demonstrated such differences. ${ }^{38}$ Although autism and psychosis did not yet occupy a central platform in theories of developmental psychology, the subjects were firmly placed on the curriculum for all new trainees in educational psychology.

In 1971, the BPS held a meeting on the implications of the Summerfield Report in which it was noted that the closure of subnormality hospitals had meant that many new responsibilities were falling on the shoulders of educational psychologists that had not been envisaged in that report. In particular, educational psychologists were being asked to oversee the transfer of responsibility for children previously designated 'severely subnormal' and 'mentally defective' from local health authorities to LEAs. They were also being asked by local authorities to assume responsibility for children under care orders and those who had previously been at approved schools, and also for reorganising children's departments into social service departments with a wider responsibility for child welfare. Finally, they were being asked to establish local authority and other assessment units for 'handicapped' children. The committee conceded that the Summerfield recommendations of working towards one educational psychologist per 10,000 schoolchildren had not gone far enough and that more money was desperately needed to enable the training of many more candidates. All of this information was to be conveyed to the Secretary of State for Education. ${ }^{39}$ These changes stimulated the movement sparked by the new 
autism psychologists to assess and attend to children's psychological problems from a new perspective.

In March 1975, the DES issued circular no. 2/75, 'The Discovery of Children Requiring Special Education and the Assessment of Their Needs'. This circular removed power from members of the medical profession to determine to which schools children who required special education should be sent. The power to decide on a placement was instead given directly to educational psychologists, who were thereafter required to relay all information to the educational authorities. This placed a major demand on their time and limited the services that they could offer to children. These became increasingly concerned with assessment and placement rather than treatment. ${ }^{40}$ This transition also led to the establishment of new centres, such as the Educational Guidance Centre in Brixton, London, directed by R. A. Porteous, which provided 'a diagnostic service and informal education for children unable to maintain attendance at an ordinary school because of acute behavioural difficulties. ${ }^{41}$ These centres provided stop-gaps for children between educational placements and created a new landscape of children with no fixed schooling placement. For example, at one child guidance clinic in Brixton in the mid-1970s, staff began to observe a growing number of referrals of schoolchildren who had been excluded from school and were waiting to be given new placements. ${ }^{42}$ Increasing delays were also noted with regard to the placement of children as a consequence of the administrative changes following circular $2 / 75$. In 1979, staff at the Brixton clinic noticed 'a continuing severe pressure on the Unit's work [of] referrals of children whose educational placement has already completely broken down, whether in ordinary or special schools. ${ }^{43}$ These referrals could not be managed at the rate at which they were being referred, and families were reported to experience many frustrations due to such delays. In large part, this was due to the fact that children could not be suitably classified and placed with the support of the multiple agencies that were required to co-operate in such classificatory procedures.

After the DES had issued circular 2/75 in 1975, educational psychologists started to play a significant role in ascertaining autistic children as well as 'subnormal' children and arranging their placements. The number of educational psychologists increased steadily from the late 1960s following the publication of the Summerfield Report 
in 1968. In 1967, there were 375 full-time educational psychologists employed by local authorities, but by 1972 this number had risen to $638 .{ }^{44}$ In 1979 the figure had risen further to 935 and by 1983 it was over $1,000 .{ }^{45}$ In conjunction with teachers and parents, this new professional group began to appropriate the language of specific learning problems and autism that spread throughout the primary and secondary educational system.

In relation to this shift, the early 1970s also saw a major push to increase numbers of speech therapists employed by health authorities following the publication in 1972 of the Report of the Committee of Enquiry into Speech Therapy Services (Quirk Report). Following the Education (Handicapped Children) Act 1970, more speech therapy services for children were required because increasing numbers of children were entering the education system. In 1972, the Quirk committee reported that in England, Wales and Scotland, well over 300,000 individuals were in need of speech therapy services and that 270,000 of these were children. ${ }^{46}$ They urged schools of speech therapy to attain a target intake of 350 students per annum by 1982 at the latest. This target was reached in 1977. In 1972, 820 speech therapists were employed by health authorities across the UK, each taking on around 100 patients, making a total of 82,000 patients. In 1978 , this number had risen to 1,376 speech therapists serving a population of around $137,600 .{ }^{47}$ Ten years later, it would increase to 3,000 therapists serving 300,000 patients. ${ }^{48}$ This was a massive expansion of a service that had previously been offered to an exclusive few.

With growing numbers of children being assessed via social and educational services, and with the category of 'autism' listed in the Chronically Sick and Disabled Persons Act 1970, the diagnosis of autism became increasingly popular to designate a child who had specific needs that could not be summarised using any other diagnostic term. The diagnosis of 'maladjusted' did not help educational psychologists to generate a detailed understanding of a child's educational needs, whereas 'autism', in its new incarnation as a kind of sensory impairment, was useful in enabling educational psychologists and speech therapists to put together teaching plans and advice in the context of the education system. It was via this entry into the education system that the term autism would begin to appropriate new meanings associated with assorted types of 'impairments.' This new 'autism' would become 
increasingly important in the description of children's behaviour in multiple contexts as the term came to imitated and replicated across all professional groups working with children, in particular within the education system. The term would also become increasingly dissociated from professionals working in family services, as 'social work' became a generic category and more educational professionals began to appropriate the term and adapt its meaning.

\section{Epidemiology, schooling and 'social deprivation'}

The closure of mental deficiency institutions in the wake of the 1959 Mental Health Act, the Seebohm reforms and the slow integration of all children into the education system were transforming ideas about social work and what it meant to educate and integrate all members of a population into society. In 1970, Rutter, Tizard and Whitmore's study on the Isle of Wight was published, following an expansion of the remit to generate 'a comprehensive picture of "handicap" in a total population of children who lived in a defined geographical area'. The study had also sought to assess the need for social service provision for that population. Rutter et al. had defined 'handicaps' in three groups, namely: 'intellectual or educational retardation, emotional or behavioural problems and chronic or recurrent physical disorders (including neurological conditions). ${ }^{49}$ The study was published in book form with a simple title that bore witness to its grand social objectives: Education, Health and Behaviour. Rutter et al. considered their results to be translatable to populations across Britain, provided that other social factors were taken into account.

Using a combination of intelligence tests, medical tests, teacher questionnaires and parent and child interviews, they argued that from a total population of 2,199 children aged between nine and eleven, 354 suffered from 'some form of handicap' that caused a 'considerable interference with their ability to lead a normal life.' They then inferred from this finding that at least one in every six children within an average population would require some form of special educational provision. They argued that 3.4 children per 1,000 had severe intellectual retardation', but that 8 per cent of all children had 'intellectual and educational difficulties. ${ }^{50}$ Rates of children with physical handicap were reported 
to be 5.7 per cent. ${ }^{51}$ The proportion of children with 'psychiatric disorder' involving 'suffering in the shape of anxiety or unhappiness' or 'conflict between the society and the child, bringing trouble to both' was rated at 6.8 per cent. ${ }^{52}$ Although there were crossovers between some of these groups, the figures gave an estimation of the extent of social services that were required to cater for each unique problem. Rutter et al. also found that, whichever investigative method they used from teacher questionnaires to psychiatric interviews - 'emotional and behavioural disorders were considerably commoner among children with intellectual retardation or with specific reading retardation than among control children., ${ }^{53}$ Further studies confirmed relationships between children with specific and non-specific intellectual problems and what was regarded as 'abnormal' behaviour. ${ }^{54}$ Rutter later claimed that there was a relationship between 'low IQ' and 'psychiatric disabilities and a whole range of deviant behaviours. ${ }^{55}$ What is important to recognise here is that, in light of the major social reforms, classificatory systems used to label and categorise children were in flux, to such an extent that when working on social planning, psychologists disregarded clear distinctions and divisions between the mentally deficient and the mentally ill - distinctions that had focused researchers throughout the function of mental deficiency law and had structured the work of many human relations psychologists and child guidance workers. Psychiatric epidemiologists embraced the freedom that social reconstruction was engendering with an open mind about the new boundaries that would be set about the form and limitations of the developing mind.

In 1973, Margaret Thatcher, then Minister of Education, proposed a committee 'to review educational provision in England, Scotland and Wales for children and young people handicapped by disabilities of body or mind. ${ }^{56}$ Rutter had previously met with Thatcher and had discussed some of the findings of his research with her. ${ }^{57}$ Because the Isle of Wight study was so comprehensive and claimed to have measured the total need for psychiatric services within a geographic area, the resulting Warnock Committee based many of their plans for special educational provision directly on that report. In their 1978 Report, Mary Warnock and her colleagues referred to the Isle of Wight study as 'the most detailed study of the incidence of intellectual and educational retardation, psychiatric disorder and physical handicap' ever conducted..$^{58}$ 
The study sparked a number of later comparative surveys generating further statistics that could be compared and contrasted with this model population. Studies in London found higher rates of psychiatric disorder and reading retardation, pointing to the possible influence of urban living. ${ }^{59}$ These social surveys formed the basis for a new style of social psychiatry that aimed to study development across populations and to explain each child's individual psychiatric problem as a sum of data based on its intellectual and behavioural outcome. It was through this style of psychiatry that the 'social' was distanced from the child's creative development and reformulated as a collection of forces that impacted upon the child at different strengths and variations. Instead of examining the internal instinctive drives that impacted on the child's mental development in the model of McDougall or Burt, Rutter and the new generation of epidemiological and experimental psychologists conceptualised and measured the external social forces that were impacting upon each child's developing mind.

As John Welshman has argued, the late 1960s and 1970s witnessed a surge of interest in the social sciences on how 'social deprivation' was 'transmitted' across generations, thereby reproducing inequalities and preventing social mobility. ${ }^{60}$ Michael Rutter was a key contributor to these discussions and developed an important and inventive way in which to employ Bowlby's ideas of 'maternal deprivation' across a wider range of social circumstances. In the late 1960s, the concept of 'deprivation' was expanded within psychological sciences and disciplines to cover all forms of 'social deprivation', not just 'maternal deprivation', and this is how new epidemiological researchers such as Tizard and Rutter understood it. ${ }^{61}$ Writing in 1970, Michael Power from the Social Medicine Research Unit at the London School of Hygiene and Tropical Medicine argued that:

It is widely recognised that adverse family, school and neighbourhood circumstances impair a child's healthy development. A discussion of such deprivation must be concerned with the social inequalities that are to be found in the way that we arrange our society, with its market economy and class divisions; in particular the strong element of competitiveness and of unequal opportunity that bears heavily when certain groups of the population e.g. the poor, the chronic sick, the coloured immigrant. ${ }^{62}$ 
Power, along with those working for the MRC in the 1960s and 1970s, began to employ the concept of 'social deprivation' to describe the effects of economic, social and cultural failings on the developing minds of children. In fact, they employed the term in a similar way to Bowlby's concept of 'maternal deprivation' but included in it a range of other forms of poverty, scarcity or lack. The psychological outcomes of such deprivation were many and varied, they argued, but there was no doubt that psychological development could be thwarted or impacted by 'social deprivation. In the 1970s, this idea of 'social deprivation' differed from models of 'sensory deprivation' that were being put forward by Hermelin and O'Connor and others to explain the development of autism. However, the 1970s would witness the amalgamation of these ideas as more educational psychologists and child psychiatrists sought to understand and describe the causes of the phenomena that they were witnessing in the new population of schoolchildren. By this time, many were arguing that understanding autism was fundamental to understanding wider issues within social development and social deprivation. For example, John Wing argued that autism should be regarded as a 'paradigm for looking at the problems of social psychiatry and community care' as the 'handicaps' associated with it 'can be described in detail and methods for overcoming them or compensating for them are now beginning to be available. ${ }^{63}$

Speaking in 1970, Mary Wilson, Staff Inspector for Special Education, Inner London Education Authority (ILEA), pointed out that by 1970, the word 'deprived' was being employed in educational circles in four different ways. First, following the Curtis Committee, it was used to describe children who were 'deprived of a normal home life', this leading to 'educational backwardness' or 'emotional disturbance.' Second, to describe children in poverty who were 'deprived of good material things in life such as adequate food, good housing, [and] clothes'. Third, to describe 'cultural deprivation' leading to 'acquired intellectual handicap' and 'delay in the acquisition of language skills' because of 'insufficient variety of play materials and insufficient opportunity for sharing activities with interested adults'. Finally, it was used to describe 'emotional deprivation which is found in children who have been from an early age and for a long time deprived of normal parental care. ${ }^{64} \mathrm{Wilson}$ argued that many children including 'the brain injured, the psychotic, the delinquent, and the deprived', pointing out that most of them had 
suffered some deprivation, even though the outcome was heterogeneous. ${ }^{65}$ In other words in the 1970s, psychologists such as Wilson began to believe that they could measure social deprivation as it impacted on individual problems in psychological development. ${ }^{66}$

Whereas Freud, Bleuler, Anthony and Cameron had shifted their attention onto the hallucinatory aspects of 'autoerotism' and 'autism' in attempting to understand the most significant stages of children's psychological development, researchers at the Social Psychiatry research unit studied 'autism' as an unknown category that had the promise to elucidate the most significant stages of socialisation and to explain the outcome of both social and sensory deprivation. Instead of focusing on individual cases, Maudsley researchers of the 1960s focused on the study of total populations of autistic individuals. Eysenck's research techniques, which had turned the study of unconscious drives into measurable behaviouristic reflexes, had enabled the study of autistic and psychotic phenomena using the model of statistical psychiatry. The impact of this on the conceptualisation of all psychological problems in childhood was significant and continued to generate effects.

\section{How British sociology met autism}

By the early 1970s, the thriving interest in autism and its causes amongst a new generation of epidemiological and experimental psychologists was coupled with a growing critique of approaches to child development based on the study of human relationships. The controversy over Bowlby's report on maternal deprivation had, in fact, become so widespread by the 1960s that the World Health Organization issued a public health paper that reassessed the debate. ${ }^{67}$ Epidemiologists and experimental psychologists had used new methodologies to challenge Bowlby's claims that mothers were the only people who could offer emotional security to children and also his belief that psychoanalysis was the only science that could explain early emotional development.

The impetus for these investigations came from a rapidly developing field of sociological research that was generating new methods to address and understand detailed aspects of family and social life. As Mike Savage has argued, British sociology came of age in 1962 when the journal New Society was founded to propagate the wisdom of the 
social sciences amongst policy-makers, educationalists and other professionals. This stimulated a new interest in the social sciences in Britain that saw their entry into the syllabi of many university departments as a critical challenge to arts and humanities education. Much British sociology of the 1960s was focused on the study of everyday life and interaction, the normal population rather than the deviant classes of the previous generation of sociological investigation. As Savage has pointed out, it represented a political movement in that it sought to present a new perspective on social interaction, a new vision of society. Post-1962, British sociology also anchored itself as a unique discipline, rather than following the earlier practice of merely gathering information with an overarching theme of society, progression and evolution. ${ }^{68}$ It enabled new theories of child development to be formulated that did not follow the quasi-evolutionary models of development and maladjustment that had been propagated by Cyril Burt and Bowlby.

By the 1960s, there were a plethora of studies that used new statistical methodologies in order to answer age-old problems concerning child development and the impact of parental and social determinants on psychological problems. Characterising this shift, Simon Yudkin, consultant paediatrician at the Whittington Hospital in London, worked with the Council of Social Welfare to persuade numerous university departments to conduct interview research with mothers who left their children in nurseries whilst they went out to work. Working Mothers and Their Children (1963) argued, against Bowlby, that working mothers could indeed produce psychologically healthy children, and that early psychological development was dependent on numerous factors. ${ }^{69}$ Yudkin's other work also drew further attention to the fact that poverty, a social determinant, was linked to poor nutrition in the mother's pregnancy and in early childhood, and that these factors were associated with perinatal mortality, growth and intellectual development. ${ }^{70}$

In the early 1960s, Rudolf Schaffer, a former colleague of Bowlby's, and Peggy Emerson had begun following a group of sixty mothers and their children in Glasgow in order to track their children's development using sociological techniques. They were interested in 'the development of social attachments in infancy' and how these were formed throughout the developmental process. They qualified Bowlby's category of 'attachment' to distinguish 'indiscriminate' and 'specific' attachments, and argued that infants did not develop 'specific' attachments 
until around four to six months and that these increased in intensity until around nine months, falling off slightly when the infant was learning to crawl and walk, before peaking again at eighteen months. Their argument, backed up with much quantitative data from numerous interviews with the mothers, was that infants developed indiscriminate' attachments before forming specific bonds, and that these indiscriminate attachments continued after specific bonds were formed. These 'pre-social' attachments were part of a learning process through which the infant began to discriminate important bonds and that this 'innate behaviour propensity' was 'in the beginning not a truly social activity' but only became so through 'contact with a particular kind of environment', meaning a stable familial bond. They also downplayed the significance of mothers as the only caregiver, arguing that many infants formed their strongest attachments with their fathers or other family members. ${ }^{71}$

These debates covered much of the ground that had been traversed in the controversial discussions between Anna Freud and Melanie Klein in the 1940s concerning the importance of the early stages of life to the development of psychological mechanisms that enabled ego development and the formation of relationships. However, instead of describing and elucidating the unconscious instinctive drives that structured social interaction, they highlighted the complexity of environmental factors that could impinge on the infant's capacity to form social bonds. For Schaffer and Emerson, describing social development was not so much about articulating the drives for human relations as it was about defining the ways that sometimes functioned and the subsequent impact of this on a child's mental stability. As they argued: 'Whom an infant chooses as his attachment object and how many objects he selects depend, we believe, primarily on the nature of the social setting in which he is reared and not on some intrinsic characteristic of the attachment function itself. ${ }^{\prime 2}$ They sought to understand attachment not as a problem of relationships but as a problem of 'social setting'.

Rutter also employed the arsenal of experimental methods and statistical techniques derived from sociological sciences to measure 'family activities and relationships', arguing that this could enable a clearer understating of how environment affected development. ${ }^{73} \mathrm{He}$ also questioned Bowlby's theories of maternal deprivation, arguing that it was not separation per se that caused psychological problems 
in children, but rather the circumstances surrounding that separation. Rutter's popular Penguin paperback, Maternal Deprivation Reassessed (1972), sought to topple Bowlby's monopoly on the topic of emotional development and the causes of psychiatric disorder in children. For example, using epidemiological evidence on children whose parents had divorced, he claimed that some children were 'invulnerable' to deprivation and that those from broken homes were more likely to be affected by the discord rather than the separation itself. He also drew from Shaffer and Emerson to argue that mothers were not always the most significant figures in the formation of children's early bonds, and that other figures also held a significant influence. ${ }^{74}$ Furthermore, he quoted Jack Tizard's wife, Barbara Tizard, who had conducted observational studies of children reared in institutions from birth to eight years and found that these children did not show any impairment in intellectual function if they received enough intellectual stimulation, hoping to prove that it was not 'maternal deprivation' that caused intellectual delays but other distinct factors. ${ }^{75}$ Steven Wolkind, of the Family Research Unit at London Hospital Medical College, studied 'affectionless psychopathy' in institutionalised children and he and Rutter conducted an epidemiological study of children who had been brought up in care, in order to understand the breadth and depth of their psychological problems. ${ }^{76}$ These were not only caused by 'maternal deprivation' but multiple kinds of social deprivation.

Throughout the 1970s until the early 1980s, Rutter then embarked on a series of other major survey studies that interrogated the social world as a producer of psychiatric disorder. Cycles of Disadvantage (1976) explored the impact of everything from wealth inequality, housing, occupational mobility, crime, racial discrimination and schooling to both psychological and social stability. Rutter argued that the deprivation that causes psychiatric disorder is not just maternal deprivation but social deprivation in all its forms. Social science could explain much more about the causes of psychological problems than any mother and baby study could on its own. Fifteen Thousand Hours (1979), the number of hours that an average child spends at school, the most important 'social institution' in industrialised societies. The book investigated the possible impact of all this time on the child's psychological stability. Changing Youth in a Changing Society (1979) used epidemiological and developmental studies to think about the nature 
of adolescent behaviour and the impact of social disadvantages such as poverty, overcrowding and lack of resources on this behaviour, thereby aiding policy advisers. Juvenile Delinquency: Trends and Perspectives (1983) used theories of psychological motivations, such as aggression, to understand delinquency across the lifespan and its relation to social inequalities. As with the Isle of Wight studies, many of these studies presented a complete picture or snapshot of children's lives and experiences and the multiple social forces that impacted that development. This picture was far more complex than a mother and baby portrait.

With specific regard to the theory of autism, it was actually two sociologists who would generate the most significant new methods for approaching autism within theories of child development in the 1970s. The work of John and Elizabeth Newson fitted neatly into the development of new sociological expertise, building a new model of how everyday normal British society functioned. They argued that when considering 'social development' in children, one should not limit oneself to development schedules, but rather think about the multiple influences that infants and children perceived when entering the social domain. In the late 1950s, the Newsons had established the Child Development Research Unit at the University of Nottingham through which they produced studies of infant care such as their classics Infant Care in an Urban Community (1964), Four Years Old in an Urban Community (1968) and Seven Years Old in the Home Environment (1976), which analysed interviews with over 700 mothers in Nottingham about their child-rearing practices and experiences with their children in the first, fourth and seventh year of life. More social surveys than psychological studies, the Newsons argued that parental attitudes had as much influence on a child's psychological development as parental behaviour did. Their studies brought the immediate social environment of the children into stark relief, discussing attitudes and behaviours from discipline, smacking and guilt to public approval, love, kissing and even watching television. Their aim was to show that child development was part of a wider cultural and social network, thus sharing much in common with Maudsley researchers such as Tizard and Rutter.

The Newsons were also interested in 'handicapped' children and their experiences, working on the day-to-day life of children with cerebral palsy in the homes. In 1969, they teamed up with the Nottingham and District Society for Autistic Children, which was establishing a 
school, a collaboration driven by their own parental needs. This enabled liaison with the local authority and the Newsons quickly established themselves as specialists in the field of autism and therefore saw most children with autism in Nottinghamshire, also receiving referrals from Leicestershire, Lincolnshire and Derbyshire. ${ }^{77}$ In the late 1970 s, in line with the growing significance of autism to understanding child development, they established a major study of the way that autistic children functioned in social contexts and they collaborated with the Department of Health in effecting policy changes.

These studies all came to similar conclusions, pointing out that everything from schooling and social change to genetic disorders and handicapping conditions had an impact on child development. To think that the only influential forces impacting psychological development were parents was thoroughly misguided and wholly outdated. There were so many factors that could influence a psychological outcome. However, there were still some conflicts to these approaches. For example, whilst Rutter was, on the one hand, dabbling in the new British sociology, he was, on the other hand, building up and clarifying classification methods in child psychiatry and affirming autism as a unique cognitive impairment. Child psychiatric diagnoses largely remained framed by the needs and categorical systems of adult psychiatry and were thus restricted in their scope and capacity to truly reconceptualise child development in relation to social change. However, this began to change in the 1970s as the 'autistic spectrum' expanded the limits of this crucial psychological term. This opened the floodgates for psychological researchers to re-orient their theories concerning social development in children.

Michael Rutter, language and autism

In 1970, the Journal of Autism and Childhood Schizophrenia was established under the editorship of Leo Kanner, and Michael Rutter was appointed as an Associate Editor representing Great Britain. The aim of the journal was to bring together researchers 'for the purpose of relieving the sufferings of psychotic children and their families.' It claimed to have no theoretical bias in approaching this task but simply the aspiration 'to promote scientifically ascertained observations and facts from every source which can widen our horizon. ${ }^{38}$ The editors stated that the 
journal was 'devoted to all psychoses and severe disorders of behaviour in childhood. ${ }^{79}$ This claim directly linked the category of psychosis to 'behaviour disorders'. The first edition of the journal in 1971 featured an article by Rutter and Lawrence Bartak on the 'Causes of Infantile Autism' that highlighted Rutter's proposition that a 'language and cognitive defect constitutes the primary handicap in autism. ${ }^{80}$ Their theory was that the autistic child has a 'central defect in the processing of any sort of coded, meaningful or temporarily-patterned stimuli. ${ }^{81}$

This proposition differed from that of Hermelin, O'Connor and Frith, which explored sensory impairments and their impact on cognitive processes. Rutter instead wanted to clarify the exact cognitive or thought processes that were associated with autism and which subsequently led to the symptoms of withdrawal. Therefore, instead of focusing on the way that sensory impairments could be tested, he focused on language as the key area where any cognitive defect would be evident. This focus on language impairment was also a function of the administrative and bureaucratic system in which the category of autism was born. Because 'language impaired' children were being integrated into the education system via the growth of speech therapy services, there was a burgeoning interest in language impairment.

At the same time, similar policy shifts in the USA meant that the growing cognitive psychology movement there was increasingly focusing on language development, further stimulated by the work of the emerging linguistic star, Noam Chomsky. Chomsky was one of a group of researchers based at the Massachusetts Institute of Technology and the universities of Stanford and Harvard who challenged a model of behaviour dependent on the stimulus-response paradigm and instead described behaviours in terms of a nesting and clustering of programmes of action that an individual organism ran through in order to reach its goals. In Britain, scientists such as W. Grey Walter, a key figure in the development of EEG studies, developed similar approaches. ${ }^{82}$ As Rhodri Hayward has argued, Grey Walter was also an advocate of using EEG recordings and computer modelling to explain desire and emotional attachments, although his views were never accepted in the mainstream. ${ }^{83}$ This 'cognitive' model drew primarily from computer technology and information processing rather than animal models of action. ${ }^{84}$ Chomsky's work aimed to use the theory of language as a model for psychology in general and he published a damning critique of Skinner's work on language as 
a form of behaviour. ${ }^{85}$ Chomsky maintained that it may eventually be possible to study the 'built-in structure of an information (hypothesisforming) system' that enabled subjects to form grammatical language, also suggesting that this system was innate. ${ }^{86}$ In his monograph, Syntactic Structures, he had also argued that syntactical relations could be used to construct a general theory of grammar. ${ }^{87}$ Chomsky's work was well known amongst child psychiatrists, developmental psychologists and speech therapists in the UK by the early 1970s; in particular it was quoted in relation to the use of behavioural techniques in the teaching of language skills to children who could not talk. ${ }^{88}$

These theories encouraged new work on language development in Britain, although they had not gained full acceptance by the new generation of epidemiological and experimental child psychologists in the 1960 s and 1970s, partly because they clashed with Piagetian models of development. Piaget's work had been highly influential on UK educational practice and training. For example, the 1967 Plowden Report for the Central Advisory Council in England stressed the importance of Piaget with regard to understanding intellectual, social and cognitive development and sensory integration in developing children. ${ }^{89}$

In October 1975, Piaget and Chomsky, together with a group of distinguished psychologists, linguists, epistemologists, neurobiologists and social scientists, held a conference to discuss the disparity between Piaget and Chomsky's respective views of language acquisition. Whereas behaviourists such as Skinner had ignored the question of language acquisition almost entirely, Piaget's theories of genetic epistemology presented a model of this process that conflicted with Chomsky's model of generative grammar. In his opening presentation, Piaget put forward his central view of cognitive development:

Knowledge does not result from a mere recording of observations without a structuring activity on the part of the subject. Nor do any a priori or innate cognitive structures exist in man; the functioning of intelligence alone is hereditary and creates structures only through an organisation of successive actions performed on objects. ${ }^{90}$

Piaget argued that Chomsky was incorrect in claiming that there was an 'innate fixed nucleus', an a priori cognitive structure for language acquisition. In his view, language was the outcome of an infant's biological and behavioural auto-regulations in its interaction with the external world. 
Because these interactions were limited by physical reality, both external and internal to the organism, each infant would necessarily develop the same systems for thinking that enabled both language acquisition and syntactical regulation. ${ }^{91}$ In other words, all logico-mathematical structures in the mind, including grammars, were formed through 'an exact and detailed adaption to reality' rather than pre-formed prior to that interaction. ${ }^{92}$ Chomsky, on the other hand, maintained that the capacity to develop grammatical language was innate.

Rutter and other new autism researchers were slightly in thrall to Chomsky's work emerging from the USA and they sought to emulate its significance in their own work. It was actually quite an unusual move for Rutter to want to develop a cognitive model of autism, given that the concept had been drawn entirely from models of subjectivity that were based on an infant's adaptation to reality via interactions with people and other objects, as in the work of Piaget, but also Isaacs and others. In developing a cognitive model of autism, Rutter was also, by default, developing a cognitive model of subjectivity and the origins of human relationships. Prior models of developing subjectivity had drawn from instinct theory and Piagetian models of mind-object interaction. The idea that the development of subjectivity and relationships could be studied cognitively was new.

Since the mid-1960s, Rutter had argued that 'speech disorders' and difficulty with language characterised children with 'psychosis' and 'autism. ${ }^{93}$ He later argued that autistic children usually scored well on block design tests and object assembly because these tests did not require the concepts of abstraction, symbolisation and logic that were associated with language. In contrast, they always scored badly on tests for picture arrangement or other things that did require those symbolic skills. ${ }^{94}$ In 1968, Rutter argued that the primary deficit in autism was a language problem and that this then gave rise to the other symptoms that were secondary. He quoted studies such as Hermelin and O'Connor's to argue that autistic children's difficulty in comprehending sentence structures showed that their memory of words was independent of the meaning of those words. Rutter claimed that autistic children suffered a 'cognitive and perceptual deficit' rather than a problem with emotional attachment. He acknowledged that it was 'difficult to differentiate between poor social perception and a general impairment in symbolic functioning or language comprehension'. Nevertheless, he 
argued that the study of 'speech disorders' provided the key to understanding child psychosis and autism. ${ }^{95}$

Instead of drawing from psychoanalytic models of child development, or those based on the model of instincts and emotions, Rutter turned to neurology and to neurological studies of language processing and aphasia. In 1975, Rutter, Lawrence Bartak and Anthony Cox published the first part of a major 'Comparative Study of Infantile Autism and Specific Developmental Receptive Language Disorders' in the British Journal of Psychiatry. ${ }^{96}$ These studies argued that, although there were similarities in these groups, comparisons showed that autistic children demonstrated particular 'deviant' forms of language such as echolalia, pronoun reversal, stereotyped utterances and metaphorical language. In the case of children who only had language disorders such 'deviant' speech was not prevalent, but this group was much more likely to have defects in articulation. The language 'deviance' and impaired usage of spoken language and gesture seen in autistic children was different from the problems seen in other language-disordered children. ${ }^{97}$ Figure 7 shows a section from a table of items used to discriminate between these two groups in 1977 and the discriminant function that had been calculated from the 1975 study. Discriminate function analysis demonstrated that autism was a reliable diagnosis within a wider spectrum of 'severe developmental disorders of receptive language' and further cluster analysis and statistical techniques could confirm this. ${ }^{98}$ Testing for these abnormalities of language offered a way for researchers to identify the core cognitive deficit of autism using large populations of children. The work was taken up enthusiastically internationally. For example, Giampiero Bartolucci, from the McMaster Psychiatric Unit, Ontario, argued that autistic children may be 'deficient in their ability to extract the components of structured auditory input' and that this was evidenced in their unique use of phonemic substitutions. ${ }^{99}$

It has frequently been pointed out by historians and cultural critics that the 1960s brought forth a 'linguistic turn' in multiple disciplines including anthropology, philosophy, psychoanalytic theory, literary criticism and psychology. ${ }^{100}$ The significance of this major transition for the field of child psychiatry has been little explored. However, it is clear that the study of language was becoming fundamental to all theories of autism in the late 1960s and 1970s, and that this new-found topic of interest was diverting attention away from instinct theory and 
D. Current language behavior

1. Pronominal reversal

$-0.434$

2. Use of stereotyped utterances

0.096

3. Repetition of own phrases over and over $\quad-0.001$

4. Immediate echolalia $\quad-0.022$

5. Utterance length 0.461

6. Metaphorical language $\quad-0.227$

7. Abnormal articulation $\quad 0.347$

8. Odd intonation $\quad 0.039$

9. Use of gesture to communicate -0.037

10. Communication to ask to go somewhere $\quad 0.013$

11. Communication to comment on things happening 0.251

12. Communication to report on events spontaneously -0.431

13. Communication to to report on events in response to questions 0.143

14. Communication to to answer question 'What are you doing?' $\quad 0.046$

15. Communication to chat to adult -0.168

16. Communication to ask if he can help with activity $\quad 0.129$

17. Talking to himself about his activity $\quad 0.156$

18. Displays sympathy to others 0.004

19. Creative play -0.133

20. Imaginative play $\quad-0.096$

21. Cooperative imaginative play (test situation) $\quad-0.217$

Figure 7 Section from table of items used in discriminant functions analyses, from Lawrence Bartak, Michael Rutter and Anthony Cox. 'A comparative study of infantile autism and specific developmental receptive language disorders: III - Discriminant function analysis', Journal of Autism and Developmental Disorders 7, no. 4 (1977)

fantasy formation in the minds of developing infants. In Britain, the closure of mental deficiency institutions and the growth of speech therapy services provided the perfect administrative setting for research into language problems in children. The focus on autism as a cognitive disorder, and specifically one associated with language, was strongly associated with this political, social and cultural setting.

The closure of deficiency institutions had served as the impetus for the first large-scale studies of 'speech disorder' in children. ${ }^{101}$ The concept of a 'speech disorder' could be traced back to the work of the French physician Paul Broca and the German physician Carl Wernicke in the nineteenth century on areas of the brain responsible for language and how damage to these areas affected adult speech. ${ }^{102}$ The term 'disorder' began to be used frequently in British writings on speech problems 
at the start of the twentieth century. ${ }^{103}$ In the 1930s and 1940s, some neurologists such as Russell Brain began to use this approach to understand speech problems in childhood. ${ }^{104}$ In 1959, T. T. S. Ingram from the Department of Child Life and Health at the University of Edinburgh argued that 'speech disorders' were characterised by the 'retarded development of the ability to articulate speech sounds accurately', but which 'cannot be attributed to the presence of mental or emotional retardation or physical disease. ${ }^{\prime}{ }^{105}$ After 1959 , the wider availability of child subjects who would have previously been classed with 'mental defect' meant that 'speech disorders' appeared to be more common and it became possible to undertake more complex studies into their form. A growing focus on the key cognitive deficit of autism in the early 1970s helped to fuse these models, and neurological models of brainspecific areas gave further support to the idea of a fixed, measurable malfunction in the brain that characterised 'autism'. These changes were contemporaneous with a wider interest in the 'communication' problems of children as opposed to their emotional problems. ${ }^{106}$

Prior to the 1970s, the term 'developmental disorders' was rarely used, and when it was used, it was employed primarily in relation to speech disorders. As Gil Eyal has shown, in the USA, the term 'developmental disabilities' was first used in 1970 by Congress as part of the legislation that began the process of deinstitutionalisation. ${ }^{107}$ In North America, 'developmental disorder' began to be used more freely in the early 1970s to include 'mental retardation, learning problems, communication disorders, and visual-perceptual and perceptual-motor problems. However, it was Rutter's work in Britain in the mid-1970s that fused the study of language disorders with the study of autism and presented both as a form of 'developmental disorder'. The introduction of the term 'pervasive developmental disorder' in DSM-III, with autism as a subcategory, sealed the description of autism as a problem concerning delays in development rather than a condition caused by emotional determinants.

This fusion was accompanied by a more general description of 'neurodevelopmental' problems in children. The concept of 'neurodevelopment' became established in British literature on child development in the early 1970s. In 1973, Kingsley Whitmore, along with Martin Bax from Guy's Hospital, published a paper in the Lancet arguing for the introduction of a short battery of 'neurodevelopmental' tests for 
children. ${ }^{108}$ The term 'neurodevelopmental' was clearly instituted as part of the demographic shift towards the inclusion of all children into the comprehensive education system. The idea of 'neurodevelopmental' disorders enlightened teachers about atypical behaviour and also justified integration, unlike prior terms such as 'handicapped' or 'defective. Although these unfortunate terms had not entirely died out in the 1970s, 'neurodevelopmental' at least had the potential to surpass them as a more sophisticated way to depict and describe the variations that could occur throughout children's development. Along with epidemiological sciences, 'neurodevelopment' opened up the study of child psychology to new scientific horizons and diminished terms such as 'mental defect' that were associated with social exclusion. In 1977, Cecil M. Drillien from the Department of Child Life and Health at the University of Edinburgh edited a volume titled Neurodevelopmental Problems in Early Childhood that argued for a radical rethink of the way that 'neurodevelopmental problems' were managed in childhood, arguing for better definition and responses that were proven to be effective. The authors were concerned with the 'commoner mental, neurological, sensory and behavioural disorders'. The 'neurodevelopmental' nature of these problems was becoming more widely recognised in families, schools and other social settings. And with this awareness came a burgeoning language to describe the various ways that the development of the brain and its functions could be affected. ${ }^{109}$ This new language increasingly replaced the language of instincts as the umbrella theory for understanding child development and its anomalies.

Even as early as 1972, the Times Educational Supplement had published a report by Lorna Wing that argued that autism was a 'condition of multiple neurological impairments involving language, perception, and organisation of movement' caused by many factors including genetics, infections and other problems affecting foetal development. She pointed out that although 'this formulation cannot justifiably be called a theory', it has 'the advantage of recognising the multiplicity of problems that have to be taken into account before any hypothesis as to the nature of childhood autism can be accepted.' ${ }^{110}$ Indeed, the proposal that 'neurodevelopmental disorders' better defined autism that emotional or imagination difficulties did help to expand the domains of research that could be included as part of a wider strategy to understand 'autism'. 
In the late 1960s and early 1970s, Michael Rutter managed a clinic for autistic children at the Maudsley Hospital where children were referred from all over the UK and even from the USA. ${ }^{111} \mathrm{He}$ quickly became an 'acknowledged expert' in the field of autism study and was asked by SAC to act as the referring psychiatrist to their schools. ${ }^{112}$ Between the mid-1960s and early 1970s, the majority of suspected cases of autism in Britain were referred to Rutter's team. Rutter and colleagues corresponded widely with teachers, parents, educational psychologists and speech therapists across all major English counties from Essex and Kent to Devon and Durham. They also saw cases, and maintained contact, with many parents and professionals in Scotland, Wales and Northern Ireland. In much of this correspondence, case formulations or summaries highlighting the salient features of autism were used as a basis for descriptions of the child's problem to various professional and non-professional groups.

Children referred to the autism clinic at the Maudsley were tested using a selection of developmental indices and intelligence tests, which would take up to four hours, in which psychologists aimed to get a thorough understanding of the child's cognitive capacities. After the 1970 Acts that expanded education for all, children were no longer considered purely in terms of their 'intelligence', but their overall cognitive abilities were assessed as well. A number of tests were employed in this period to test capacities. As well as Hermelin and O'Connor's tests, these included standardised testing scales such as the Merrill Palmer scale of intelligence, the Vineland Social Maturity Test, the Reynell Developmental Language Scale and the Illinois Test of Psycholinguistic Ability. ${ }^{113}$ Many of these tests enabled comparisons of linguistic and non-linguistic abilities, hence the focus on this aspect of autistic children's cognition. A typical account of an 'autistic' child read 'probably of high ESN level on non-verbal material [but] ... he is grossly retarded in language both in comprehension and expression. ${ }^{114}$

As discussed earlier, the integration of growing numbers of children into the education system after 1970 meant that increasing numbers were labelled with speech disorders. Some of these children were referred to Rutter's clinic whilst others followed a different route via 
audiology and speech therapy departments within general hospitals and from there directly into special schools. In the late 1960s, J. A. M. Martin from the Nuffield Hearing and Speech Centre established a unit for the treatment of speech and language disorders at Ealing where children could be admitted with their mothers for short periods in order to train the mothers how best to treat and look after their children. ${ }^{115}$ Rutter and Martin corresponded frequently over particular cases and about general theories concerning language training in children with specific language problems and those who were autistic. Concerning the development of speech in one four-year-old boy, Martin wrote to Rutter arguing that:

It looks as though language is purely 'linguistic' responding to Brain's rather quaint idea that there are not only one word schemas but also sentence schemas, and that the child picks out an appropriate sentence which he has learnt ... He is entirely incapable of manipulating words as symbols and has to rely entirely on pre-arranged learnt structures. ${ }^{116}$

Children who presented with such unusual forms of speech became models on which debates about the development of symbolic forms of thinking were reframed. Some of these children demonstrated echolalia or other speech presentations that differed from other children their own age. Instead of using the linguistic utterances of autistic children to search for metaphoric meaning, as prior child psychologists such as Isaacs had done, Rutter and the new generation of epidemiological and experimental psychologists used these utterances to search for standard differences that would be repeated by children across the total autistic population.

Looking in detail at specific cases in Rutter's autism clinic, it is easier to see how this focus on language and measurable behaviour was coupled with a shift away from an interest in hallucinations, phantasy and instinctive drives. In the case reports of children who were observed and treated at the autism clinic during the 1970s, a descriptive mode arose that gave great details about repetitive and ritualistic actions and language and highlighted an absence of fantasy and creative play. A typical description of an autistic child from 1972 stated 'limited imaginative play' and 'inability to cope with abstract concepts. ${ }^{117}$ A typical summary of one autistic boy in 1974 listed a series of 'mannerisms': 'Collects bits of paper with drawings on them (TV test card, car numbers etc.). Also [has a] treasured box of 50 diaries, collection of toy buses. Pulls lips 
twists hair when concentrating. When on swing will go into a "trance", spins slowly, peripheral gaze at books. ${ }^{118}$ Several of the children were noted to have abnormal obsessions with vacuum cleaners, lawnmowers or other unusual objects. ${ }^{119}$ Other children showed abnormal interest in particular sounds or tunes. One child, for example, was obsessed with the theme tune of News at Ten. ${ }^{120}$

Even if the child was able to describe phantasies or the contents of their thoughts, these were often relegated in a descriptive model that was searching primarily for repeatable instances of behaviour and language. It was via this continual search for repeatable behaviour and linguistic utterances that the method of epidemiological sciences actually came to structure the definition of autism in individual cases. For example, in the following summary of a 'typically autistic' child diagnosed with autism in 1975 at the age of eight, there is a marked emphasis on observation, classification and measurement that all quantitively outweigh the significance of descriptions of 'phantasies' or symbolic material.

Play: mainly collecting and classifying objects, sorting them out and manipulating them. Since 6 months ago has phantasy of a giant hook, a persecutory supreme being in animal form which he is able to draw and share with his younger brother. No phantasies about people. Mannerisms: A few remaining stereotypies such as handshaking, head nodding. Obsessed with flowers, insects, feathers, searching for them, counting them and sorting them. Collects plastic spoons in public places. Plaits great quantities of wool. Marked resistance to environmental change. ${ }^{121}$

Even though the new generation of epidemiological and experimental psychologists had not completely ruled out the possibility of hallucinations or imaginative thought in 'autistic' children, these became increasingly sidelined under the weight of measurable quantifiable behaviour and linguistic utterances.

For example, in the case of one child who was referred to the clinic in 1970 after causing violent episodes on a children's ward in a hospital, the referring doctor described him as follows:

This boy functions as a subnormal, although I believe, following a detailed examination, that the diagnosis is that of schizophrenia. I found him difficult to examine and rather restive, continually exhibiting echolalia. The boy looked vague and was very clumsy. He laughed aloud for 
no apparent reason and there were times during the examination when he adopted an attentive attitude as if he was listening to voices. I feel there is no question but that he is hallucinated. Emotionally, he was very flat, showing no warmth whatsoever ... He remains hallucinated and likes to be alone with the voices ... During all the time I have known him, he has not been aggressive to anyone, but there are times when he stamps his feet, kicks out and hits his head with his hands, probably this is a result of his hallucinations. ${ }^{122}$

Rutter responded, stating that the diagnosis was 'certainly that of infantile autism, and his subsequent course and progress has been consistent with this diagnosis'. Concerning the presence of hallucinations, Rutter pointed out that 'He certainly shows the odd behaviour that you describe in your letter but I would personally doubt whether in fact he was hallucinated. With a boy who cannot communicate it is, of course, practically impossible to tell one way or the other.' ${ }^{123}$

It was because of this that children's play began to take on very different meanings. The representation of children's play then also became focused on repetitive quantifiable actions rather than a reflection of instinctive drives. This turn away from the imagination and the fantasies of children, and the focus on their language and behaviour as repeatable items, characterised autism research in the 1970s and also characterised the definition of autism itself. The category of autism came to serve as a receptacle for children who did not think according to established models of subjective development. This new category of children presented a challenge to all other models of child development, and it was a challenge that was rapidly growing in size due to increasing diagnoses.

Rutter's tacit assumption here was that 'social relationships' were contemporaneous with the development of language, at least in the case of autistic children. Children's psychiatric case notes from the 1970s are filled with the phrases 'lack of fantasy or pretend play' or 'limited fantasy and creative play' as evidence that a child had autism. ${ }^{124}$ As studies of autistic children continued to multiply during the 1970s in the attempt to explain this central problem in child psychiatry, Kolvin's statistical studies and Rutter's speculations were transformed into claims that autistic children simply did not hallucinate or have fantasies at all. This characteristic was increasingly supported by studies emerging from the Social Psychiatry Research Unit and a consensus began to emerge there that knowledge about children's thought should work from the 'social' 
and statistical downwards to the individual case, rather than from the individual case upwards into the social world, as had been typical in psychoanalytic theory. It was just as this statistical model in child psychiatry was being established that interest in autism began to grow. This condition, which was part of a model of subjectivity, yet which denied the possibility of individualistic interpretations, was the perfect disorder through which to impose a statistical model that purported to measure the 'social' in its description of abnormal child development.

\section{'Autistic features' in context}

After Lotter's epidemiological study had defined autism according to behavioural criteria, Rutter cast the net wider in attempting to develop a behavioural definition of autism that was also distinguishable from similar psychological problems in children. Rutter argued that the 1961 working party definition of autism was too comprehensive because it included things such as over-activity and excessive anxiety, 'which do not serve to distinguish the autistic child from children with other psychiatric disorders. ${ }^{125}$ Hence, in 1968, Rutter replaced Creak's nine points with three key features that characterised autism. These were 'profound abnormalities of language development, a variety of ritualistic and compulsive phenomena ... [and] a particular variety of disturbance in interpersonal relationships.' ${ }^{126}$ Rutter pointed out that these 'features' were specific to early childhood and that they would be modified and sometimes absent in older children with the condition.

In the case reports of every child that was referred to the Maudsley in the early 1970s, these 'features' were repeated regularly. For example, in a 1975 letter from Rutter's registrar Dr M. Weiselberg to Dr Philip Graham from the Department of Psychological Medicine at Great Ormond Street, one child was described as showing 'classical autistic features in that there is a severe disturbance of peer relationships, a developmental abnormality of language and numerous manneristic behaviours dating from birth. ${ }^{127}$ These exact words were then repeated in letters to the Essex Special Services Education Department, the Helen Alison School for Autistic Children and the child's local GP surgery. ${ }^{128}$ Through letters such as these, the basic model or key features of 
autism were distributed and publicised throughout school and social work agencies across Britain. This demonstrates how a formulaic observation was used as a theory-promoting mechanism.

The idea that autism could be subdivided into separate 'features' increased the chances of a child being classed with the category. Disconnected autonomous autistic 'features' first began to be observed in children with specific language disorders, as well as those who were otherwise globally retarded and 'subnormal'. For example, in October 1970, the School Medical Officer from the Public Health Department of the Borough of Colchester, M. J. Brown, wrote to Rutter concerning a child whose parents considered him to be autistic and wanted him to be educated at an autistic school. Brown's own point of view was made clear in his claim that 'I do not believe this child to be autistic but severely retarded and the parents are quite unable to accept this'. On seeing the child, Rutter's response to Brown was that 'the clinical picture is that of a severe developmental disorder with some autistic features'. He then suggested that he be sent to an autistic school, 'although he is not strictly speaking autistic'. The boy was later accepted at an autistic school; however, it was found not to cater for all of his needs. In 1972, Rutter contacted Colchester Social Services Department requesting that a community social worker be appointed to the family to provide them with additional support in dealing with the boy, whom he described as 'a severely handicapped child with a profound global language disorder, autistic features and some intellectual retardation. ${ }^{129}$

Concerning the diagnosis of autism in a seven-year-old child who was referred to the clinic in 1978, Lucy Ellis, School Medical Officer for Solihull Area Health Authority, wrote to Rutter asking whether the child should be referred to an autistic unit or a language unit for his education. She queried whether the boy was autistic because he did not exhibit visual avoidance or auditory non-recognition. Rutter's response explained his reasons as follows:

I agree with you that the boy does not show any auditory nonrecognition and that he shows little visual avoidance (although there was some indication of this at times when I saw him). As you say, he also makes some social approaches, is generally cheerful and makes some spontaneous remarks. These are all characteristics which would be most unusual for an autistic child below the age of 5 but it is not at all uncommon to see this in the milder autistic children at a slightly older age. ${ }^{130}$ 
Rutter therefore diagnosed the child with 'mild autism' but thought that a school for autistic children would not be appropriate because they tended to deal with children who were much more 'handicapped'. Rutter therefore recommended a school that took on children who were in the ESN (Mild) level of functioning. ${ }^{131}$

Autistic 'features' also came to be regarded as offshoots of primary problems in learning and development. For example, one four-yearold child whose parents had been referred to Rutter via the Society for Autistic Children in 1969 had test results that 'were well above the test ceiling' on non-verbal tasks, yet had failed most items testing speech. This discrepancy suggested autism, though the boy was not found to have any of the other symptoms associated with the condition. The senior School Medical Officer of his district had suggested that the boy be placed in a partial hearing unit, even though there was no evidence of deafness, because the emphasis there would be on teaching speech development. The child had also been referred for speech therapy at the local children's hospital but the speech therapist was uncertain as to whether what she regarded as his 'severe behavioural problems' were secondary to his 'developmental language disorder' or were causing it. After seeing the boy, Rutter thought him to be suffering from a 'profound developmental language disorder' associated with 'problems in tongue and lip co-ordination'. In later correspondence from the mid1970s, Rutter began to describe him as 'a boy of normal intelligence on non-verbal tests, who had a very specific language disorder associated with some autistic features.'. ${ }^{132}$

In the mid-1970s, educational psychologists and others working in the field of education also started to use the term 'autistic features'. Writing in 1975 about an eleven-year-old boy, who had been diagnosed with 'childhood psychosis' at the age of five, the Senior Educational Psychologist of Essex County Council described him as:

a severely subnormal boy, developing mentally at about one third the normal rate, whose behaviour shows some autistic features, but he does not in many respects fit the classic picture of the autistic child. It seemed to me that many of his 'autistic' behaviours were symptoms of either a) his developmental stage - it is normal for 3 yr olds to have violent temper tantrums, or b) his poor comprehension of instructions and of social situations or c) his inability to cope with unstructured teaching and caring situations. ${ }^{133}$ 
Descriptions such as this draw attention to the way in which 'autistic features' were becoming synonymous with infantile behaviour and early developmental stages generally.

There were several cases in which some professionals saw autism and autistic features whilst others saw none. For example, one child had been diagnosed with autism in 1976 at the age of four by an educational psychologist who said that all the 'criteria of childhood autism are present.' He was also seen by a consultant child psychiatrist, Dr Ross, who thought that the boy was 'probably suffering from childhood autism. The parents then took the child to see Dr Hugh Jolly, consultant paediatrician at the Charing Cross Hospital, who did not think that the boy was autistic and 'the label of autism was thus removed by Dr Jolly'. Dr Mackay, consultant paediatrician at the Royal Manchester Children's Hospital, also thought that the boy 'did not show the classic features of autism. When the boy was later referred to the Maudsley at the age of eight, Rutter argued that he was 'suffering from childhood autism in a mild form.'. ${ }^{134}$

Although Rutter had restricted his three key features to early childhood, at Rutter's clinic the staff relied primarily on the reports of parents and teachers for descriptions of the child's behaviour in infancy. Most children suspected of autism were not observed directly in infancy. In these cases, children would be diagnosed with 'autistic features' rather than definite 'autism. The establishment of 'autistic features' as an idea helped to affirm the label of autism within the system of government administration and also enabled the cognitive model of psychology, developed by a new generation of epidemiological and experimental psychologists, to be used to challenge wider assumptions about emotional development that were then enshrined in government policy towards families following Bowlby and Winnicott.

Rutter became increasingly important in the international arena of autism research and the theories he formulated in his clinic went on to have global significance. In 1979, the Journal of Autism and Childhood Schizophrenia was renamed the Journal of Autism and Developmental Disorders. Writing in the editorial of that year, Rutter, who had also been promoted to European editor, along with Eric Schopler, who had replaced Kanner as chief editor in the mid-1970s, explained the transition as follows: 
In order to stimulate more flexible research strategies, the title and scope of the journal have been broadened to include a wider range of developmental disorders related to autism. This carefully circumscribed broadening is also intended to clarify the developmental factors that shape the autistic symptom picture. By focusing on all types of issues within a wide span of developmental problems it is hoped that there may be a greater clarification of both the similarities and the differences between the various disorders that delay or distort the developmental process. We hope, too, that it will lead to greater knowledge on the various connections between physical anomalies of development and their psychosocial and behavioral sequelae. ${ }^{135}$

Kanner's stipulation that the journal be devoted to 'all psychoses and severe disorders of behaviour in childhood' was rewritten and, in 1972, the editors claimed that the journal was 'devoted to all severe psychopathologies in childhood'. An advertisement in the Schizophrenia Bulletin in 1975 described the journal as 'a multidisciplinary forum for the rapid dissemination of information ... [which] deals with research, theory, and therapy in all severe behaviour disorders of childhood. ${ }^{136}$ It was clear that Rutter and Schopler had ambitions to build a new style of thinking about deviations in children's development and that they saw the categories of 'autism' as central to this conceptual revolution. This was an important moment for child psychology because autism was such a central concept. Once this concept had been appropriated and defined as a developmental problem associated with language, the concept of hallucination, which had been a key concept in all descriptive psychopathology since the nineteenth century, was written out of developmental psychopathology. As autism was associated further with developmental disorders, hallucination was increasingly eradicated from the concept. The concept of autism was thereafter increasingly defined and described according to the tools that had been used to measure it.

Social development as a cognitive achievement and the birth of 'social impairment'

'Neurodevelopment' was becoming increasingly common as an umbrella term to describe childhood psychological development and its anomalies. Although Rutter sought to locate it clearly in atypical language 
function in the case of autism, the Newsons and Lorna Wing would shift the study of autism in a different direction. This new direction was more closely aligned with the radical changes occurring in the social welfare system with its focus on generic 'social service' departments. In 1975, John and Elizabeth Newson published 'Intersubjectivity and the Transmission of Culture: On the Social Origins of Symbolic Functioning', a paper that grappled with Piaget's theories of psychological development and argued for a radical rethink. Rutter wrote a report supporting this research. ${ }^{137}$ In 1963, John Flavell, a US-based developmental psychologist, had published an easily accessible summary of Piaget's theories in English that helped to popularise and promote Piaget's ideas in the anglophone world. In the late 1960s, Piaget and Bärbel Inhelder's The Psychology of the Child was published in English (going on to many editions), which also provided a concise summary of Piaget's key theories. By the 1970s, Piaget's work was widely known and widely discussed in Britain. In the 1970s, several autism researchers in Britain began to challenge Piaget's theories of psychological development in order to present their new theory of child development modelled around autism. In The Psychology of the Child, Piaget and Inhelder emphasised the importance of symbolic functioning to the establishment of cognitive structures in the process of development, arguing that after the sensori-motor period, at around eighteen months, the child develops the capacity to think symbolically. As they described it, drawing from the famous Swiss linguist Ferdinand de Saussure: 'It consists in the ability to represent something (a signified something: object, event, conceptual scheme, etc.) by means of a "signifier" which is differentiated and which serves only a representative purpose: language, mental image, symbolic gesture and so on. ${ }^{\prime 38}$ The Newsons felt compelled to critique the view that sensori-motor interactions and knowledge were primary and that the ability to represent only arose at eighteen months. They argued that the infant's most important transactions were with other human beings and that therefore their cognitive development had to be reconsidered as including aspects of symbolic thinking in early life. As they put it: 'The chid only achieves a fully articulated knowledge of his world, in a cognitive sense, as he becomes involved in social transactions with other communicating human beings. ${ }^{139}$ This was clearly not a new discovery. Many child psychoanalysts and developmental psychologists from Susan Isaacs and Melanie Klein to Anna Freud and John Bowlby had 
discussed these stages of development in great detail since the 1930s. What was novel was that the Newsons presented social development as a form of cognitive development. They were not interested in the theoretical abstractions drawn from the study of instinctive drives and their impact on unconscious mental processes. Instead, they described social development as a cognitive achievement and verified it with experimental studies.

Instead of describing the ways in which instinctive drives compelled the desire for human interaction, the Newsons argued that 'the infant is somehow innately primed to participate in complicated social rituals. ${ }^{140}$ This claim that infants had innate cognitive social structures vied with Chomsky's claims that the language faculty was innate, and with Piaget's claims that intelligence was innate. The Newsons were aware of this and sought to generate a theory of innate mental capacity that had the absence of that innate capacity as its obverse. Just as children could have intellectual impairments or 'mental deficiency', or speech and language impairments, they could also have 'social impairments' that affected the development of their innate social capacity. The difference between these impairments was a function of the support for the intellectual, language or social cognitive faculties. In the mid-1970s, the claim that the social faculty, or social capacity, was a fully formed and complete innate unit was not concluded, although it would become so by the end of the decade. It took new work on 'intersubjectivity' to bridge the gap.

Lorna and John Wing supported and popularised the Newson's work, and developed it, drawing particularly from the work of Colwyn Trevarthen from the University of Edinburgh. ${ }^{141}$ Trevarthen followed the work of William Condon and Louis Sander from the Boston University School of Medicine. Condon and Sander were using close observation of infants to argue that they responded to human speech with an ongoing 'dance', suggesting the presence of a 'primary linguistic-kinesic interaction process' in which the infant provided very early cues to the social advances of others. ${ }^{142}$ Other well-known North American psychologists such as Peter $\mathrm{H}$. Woolf at Harvard explored the exact quality of babies' cries and parental responses to these. ${ }^{143}$ Trevarthen was interested in testing these theories in detail. One significant development in the 1970s was the increasing availability of relatively inexpensive yet sophisticated video equipment to university departments that enabled 
the recording, and slow replay, of infant movements and interactions. This enabled incredibly detailed observations of infant movement and pre-verbal 'speech'. Trevarthen's work was strongly influenced by this development and his theories were more widely respected due to the support of this steadfast visual evidence. Trevarthen and Penelope Hubley had used video evidence to show that eye movements of infants were co-ordinated with hand, arm, facial and mouthing movements, in such a way that this could be considered 'pre-speech'. Trevarthen developed these ideas in terms of a theory of 'intersubjectivity', a term that he had taken from the German sociologist and philosopher Jürgen Habermas. ${ }^{144}$

The term 'intersubjectivity' can be traced back to the French philosopher Edmund Husserl's works in phenomenology. Husserl had used it to describe the way that beliefs and meanings are formed through both empathy and a shared sense of egocentric perception. ${ }^{145}$ Maurice Merleau-Ponty had discussed 'intersubjectivity' in 1945 in relation to early infant interaction with the mother when describing the infant's ability to understand shared perception, but he had not dwelt on the topic. ${ }^{146}$ In the 1970s, Habermas significantly developed the concept in response to Chomsky's theory of innate linguistic competence. As well as 'monological' linguistic competence, Habermas proposed a theory of language based on 'intersubjectively valid rules' that make mutuality of understanding possible. ${ }^{147}$ Drawing from Habermas, Trevarthen argued that intersubjective interlacing of perspectives could be ascertained in infants' relationships to their mothers even at the age of two months where infants expect particular responses from their mother and respond to what she does. They termed this 'primary intersubjectivity'. Trevarthen further argued that by the end of the first year, infants are able to engage in deictic expressions that indicate, time, space, articles and demonstrative pronouns. This he termed 'secondary intersubjectivity. ${ }^{148}$ Crossing the boundaries between psychology, linguistics, philosophy and sociology, Trevarthen and Hubley were carving out a new theory of infant development. Their research was funded, remarkably, by the Social Science Research Council of the United Kingdom, further proof that epidemiological and sociological understandings were impinging on theories of child development in this period.

Trevarthen's video evidence of 'intersubjectivity' in infants gave a new dimension to autism research and to wider theories of infant 
psychological development. The Newsons saw this as evidence of 'the primacy of social responsiveness in human infants'. They argued that in their sociological interview samples, many mothers had talked of getting 'on the same wavelength' as their babies, and suggested that these constituted 'intersubjective' processes generating shared understandings that constitute human knowledge. In summary, the Newsons argued that in using the term 'intersubjectivity':

attention is being drawn to a fundamental proposition: that the origin of symbolic functioning should be sought, not in the child's activities with inanimate objects, but rather in those idiosyncratic but shared understandings which he first evolves during his earliest social encounters with familiar human beings who are themselves already steeped in human culture. ${ }^{149}$

Some have developed this theory. The theory of intersubjectivity would be taken up by Peter Hobson, Professor of Development Phychopathology at UCL in the 1980s. ${ }^{150}$ In the 1970s, it helped to promote a particular approach to 'symbolic' play that was distinguishable from psychoanalytic approaches focused on phantasy relations.

In 1975, Lorna Wing, then based at the Medical Research Council's Social Psychiatry Research Unit, argued that 'the central problem in early childhood autism is an impairment of complex symbolic function affecting all forms of communication'. In the majority of cases this was, she argued, 'associated with other impairments of the central nervous system.' ${ }^{151}$ It was the child's 'lack of symbolic play' that characterised this impairment, and from the mid-1970s Wing focused increasingly on symbolic play and its significance. A 1977 study of symbolic play in 'autistic' and 'severely mentally retarded' children attempted to delineate out the difference between the ways that children played. It had been conducted with the help of Lorna Brierley from the Medical Department of the Inner London Education Authority and Sybil Yates from the Health Department of the London Borough of Southwark over the preceding four years. For Wing, 'symbolic play' meant that, for example, a child 'made appropriate noises while pushing a toy car' or 'pretended to drive it into a garage to fill up with petrol'. If the child played with a doll, the play should involve 'at least holding them up if they were real babies and brushing their hair, or tucking them up in 
bed'. At a higher level, it involved 'active participation in pretend play with other children' as well as 'the invention of stories' and 'modelling or drawing pictures with imaginative themes'. Children without symbolic play dealt with objects in a very different way. This involved the 'repetitive manipulation of toys or other objects regardless of what they represented' such as spinning the wheels of a toy car without using it to represent a real car. Some children played in a 'stereotyped' way that straddled the two extremes. ${ }^{152}$

In trying to draw a distinction between the retarded and the autistic, she claimed that 'no child with symbolic play has the complete autistic syndrome', although children with 'severe retardation', in particular Down's syndrome, often played symbolically. ${ }^{153}$ Her purpose in drawing these distinctions was to offer guidance to educational establishments. Whereas Tizard's 'Brooklands' experiment had highlighted the value of play in improving the lives and educational capacity of 'retarded' children, Wing argued that this would not necessarily be the case for autistic children, a largely forgotten group, and that their education needed to be rethought in terms of operant conditioning and the reduction of behavioural disturbances.

If the 1960s saw a focus on diagnostic tests and experimental studies, symbolised by Creak's nine key features of autism in 1964 and Hermelin and O'Connor's tests of sensory impairment, the 1970s saw increased focus on the systematic study of how autistic children communicated and interacted with others through language, play and other symbolic systems and how this compared to other groups.

Writing in 1970, Wing described autism as characterised by 'perceptual disorders' and 'abnormalities of language', which caused 'secondary behaviour problems'. In 1978, Beate Hermelin argued that applying tests to autistic children in relation to 'normal' children was not a useful exercise because it is neither very illuminating nor profitable to come up repeatedly with the finding that children who are ill do less well than children who are not. ${ }^{154}$ Since their 1970 study, Hermelin and O'Connor had encouraged the use of control groups matched on mental and chronological ages drawn from other clinical subgroups, such as children with speech disorders. This method had been employed by Rutter and William Yule in the mid-1970s and led to their increasing conviction that autism was characterised by a problem of language development. ${ }^{155}$ This encouraged an increase in the number 
of studies that sought to discriminate ever-more minute details about the communication and social interaction of autistic children and how this compared to communication and social interaction in 'control groups' drawn either from other clinical samples or from the general child population.

This work did receive some criticism in the 1970s. Luke Y. Tsai and Jean M. Beisler from Iowa University criticised British researchers, namely Beate Hermelin, Neil O'Connor, Michael Rutter, Linda Lockyer, Lorna Wing and Judith Gould, to argue that more research needed to look into the way in which control groups were recruited, in particular when children were selected based on matched language abilities. Tsai and Beisler pointed out that autistic children tended to do better on the Peabody Picture Vocabulary Test (PPVT) than on the Test for Auditory Comprehension of Language (TACL). Furthermore, children with other psychological disorders did much better in the TACL than on the PPVT, in particular girls. Tsai and Beisler thus criticised Frith's 1970 study and Hermelin and O'Connor's 1967 study, which had used only PPVT to measure controls, claiming that the male 'controls' probably had much lower language ability than their autistic counterparts, and that the female controls actually had much higher language abilities. They were therefore not very good 'controls'. Such critiques placed further pressure on Maudsley psychologists to develop better testing schedules that measured specifically for autism, and that enabled greater capacity to match intelligence levels.

Attempting to address some of these issues, Wing developed questionnaires for parents that were used to track differences and similarities in the very early development of autism versus other developmental conditions. Relying on parental testimony, she argued that children with autism showed evidence of perceptual abnormalities early in their development. She also claimed that their early behaviour showed similarities with that of children with congenital receptive aphasia, congenital executive aphasia and congenital partial blindness and partial deafness, even though the total clinical picture was very different. ${ }^{156}$ The inference from that was that autism was a problem of sense perception, similar to all these others, because the speech and behaviour of autistic children was affected in similar ways, which she had pointed out in 1970 (Figure 8). Wing did not leave the analysis there but went on to argue that problems in social interaction experienced by autistic 
Behaviour during babyhood

A. Percentage of children showing abnormal behaviour in each group

\begin{tabular}{|c|c|c|c|c|c|c|c|}
\hline & \multicolumn{2}{|c|}{ Autistic } & \multicolumn{2}{|c|}{ Aphasic } & \multirow{2}{*}{$\begin{array}{c}\text { Part blind/ } \\
\text { part deaf } \\
(\mathrm{N}=15)\end{array}$} & \multirow{2}{*}{$\begin{array}{l}\text { Down's } \\
\text { syndrome } \\
(\mathrm{N}=15)\end{array}$} & \multirow[b]{2}{*}{$\begin{array}{c}\text { Normal } \\
(\mathrm{N}=25)\end{array}$} \\
\hline & $\begin{array}{l}\text { Speaking } \\
(\mathrm{N}=20)\end{array}$ & $\begin{array}{l}\text { Mute } \\
(\mathrm{N}=7)\end{array}$ & $\begin{array}{l}\text { Receptive } \\
(\mathrm{N}=11)\end{array}$ & $\begin{array}{l}\text { Executive } \\
(\mathrm{N}=10)\end{array}$ & & & \\
\hline \multicolumn{8}{|l|}{ A. General problems } \\
\hline (i) Poor sleep & 30 & 43 & 18 & 20 & 33 & 7 & 16 \\
\hline (ii) Feeding problems & 35 & 57 & 27 & 30 & $80^{* *}$ & 53 & 16 \\
\hline (iii) Frequent screaming & 30 & 29 & 9 & 20 & 27 & 7 & 20 \\
\hline \multicolumn{8}{|l|}{ B. Response to physical contact } \\
\hline (i) Lack of response to cuddling & 45 & 29 & 18 & 20 & 53 & $7^{*}$ & $4^{* *}$ \\
\hline (ii) Lack of response to tickling & 25 & 0 & 9 & 10 & $0^{*}$ & 33 & $0^{*}$ \\
\hline \multicolumn{8}{|l|}{ C. Anticipation of being picked up } \\
\hline (i) Lack of anticipation & 55 & 57 & 18 & 20 & $87^{*}$ & 47 & $4^{* * *}$ \\
\hline \multicolumn{8}{|l|}{ D. Response to social contact } \\
\hline (i) Lack of response to mother's voice & 40 & 1 & 27 & 10 & 67 & 13 & $0^{* * *}$ \\
\hline (ii) Lack of social response to own family & 35 & 14 & $0^{*}$ & 10 & 40 & 7 & $0^{* * *}$ \\
\hline (iii) Lack of social response to strangers & 55 & 29 & 56 & 20 & 53 & $20^{*}$ & $16^{* *}$ \\
\hline \multicolumn{8}{|l|}{ E. Interest in the environment } \\
\hline (i) Lack of interest & 75 & 86 & 45 & $20^{* *}$ & $100^{*}$ & 67 & $4^{* * *}$ \\
\hline (ii) Very quiet baby & 65 & 70 & 36 & 50 & 40 & 73 & $24^{* *}$ \\
\hline \multicolumn{8}{|l|}{ F. Self-stimulation } \\
\hline (i) Rocking etc. & 70 & 57 & 45 & 40 & 60 & $13^{* * *}$ & $12^{* * *}$ \\
\hline
\end{tabular}

Notes

Each value of $\mathrm{P}$ is the significance of the difference from the speaking autistic children's score. ${ }^{*} \mathrm{P}<0.05$; ${ }^{* *} \mathrm{P}<0.01$; ${ }^{* * *} \mathrm{P}<0.005$

Figure 8 Table comparing behaviour during babyhood in different groups of children, from Lorna Wing, 'Perceptual and language development in autistic children: A comparative study', in Infantile Autism: Concepts, Characteristics and Treatment, edited by Michael Rutter (London: Churchill Livingstone, 1971) 
children could be directly correlated with the number of cognitive handicaps that they had. As she put it: 'The number and severity of problems such as social withdrawal, attachment to objects and routines, abnormal emotional responses to situations, lack of appropriate play, and socially embarrassing behaviour, are related to the number and severity of the perceptual and language handicaps. ${ }^{\text {. }}{ }^{157}$

Wing's work was important because she developed a new theory of social development that held both political and scientific sway. This essentially held that social behaviour in infants and children was made possible by a fully functioning central nervous system and that it was thwarted by any impairments in that system. No doubt, this was a simplified model of social development and it bypassed many of the issues raised in the Newson's theories of 'intersubjectivity'. But it was the simplicity that gave Wing's work power, both in scientific circles and in political circles. This model of social development was politically important because, unlike the models of social development put forward by psychoanalytically oriented theorists such as Susan Isaacs, Wing studied 'social development' across an entire population group, covering individuals with all capacities and capabilities. The idea of social development was then no longer tied to a model of society in which certain members were excluded and hidden away. Wing's model of social development was an inclusive model. As a political ideal, this model of society was unsurpassable, hence its immediate uptake within government circles. Unlike earlier researchers such as Isaacs, Wing was not really interested in how 'normal' or typical children developed but rather how mentally 'handicapped' and psychologically impaired children failed to develop social awareness. This failure was then used as the basis on which to build a new theory of social development. As Wing considered it, if a sensory or perceptual impairment created an atypical social response then the obverse of that impairment, as manifested in a normal child, must be the cause of a normal social response. For Wing, if infants were not impaired then they would develop normal social responses, socially and that was that.

Unlike Susan Isaacs who regarded social development as a phenomenon that occurred in all infants and children through the force of their instinctive motivations, sustained by infantile hallucinations, Wing regarded social development as a phenomenon that occurred merely because perceptual, sensory and executive cognitive mechanisms 
were intact. This was a significant difference because it suggested that an infant's thought about other people was defined by their ability to grasp external perceptual experiences. Instead of forming the basis of the unconscious mind, early thought in normal infants was merely a fact of life. Nevertheless, Wing's model was definitely not the atheoretical behaviouristic vision of the mind put forward by writers such as J. B. Watson and Hans Eysenck. On the contrary, Wing and other Maudsley psychologists offered an alternative model in place of the passionate unbounded fervent desires that had been the mainstay of psychoanalytic and human relations-style psychology. They presented a new model of social development, but instead of framing it in terms of desire, they framed it in terms of a capacity for social interaction. Some infants had this capacity, some had less of it, but it could be measured. Most importantly, it was not just a kind of behaviour but an ability to be a social subject. The new theory of autism and the autistic spectrum provided new models for thinking about human social development that were just as detailed and complex as those presented by the psychoanalysts. No one could accuse the new autism psychologists of abandoning the concept of the mind, as had been the case with Watson and Eysenck. If you understood 'social impairment' in all its complex details through statistical mapping, then you would have a theory of psychology. Nothing more was needed. Wing effectively argued that there was no need to have a theory of normal social development because society was simply the benchmark for that normality. Psychoanalytic thinkers had failed in attempting to develop an acultural and unbiased model of human development. Wing and the Maudsley psychologists sought to replace this with their new model of social development, within which the new autism, the second autism, featured as the core concept.

Anthony, Piaget, Isaacs, Klein, Tustin and others had argued that the comprehension of pathological thought in 'psychotic' and 'autistic' thinking could structure general theories of psychological development, but they had regarded it as an early stage of thought in all children. Once autism was no longer conceptualised as a normal early stage of thinking associated with fantasy, it had no psychological clout or influence. Hermelin, O'Connor, Frith, Rutter and the behaviourists in the USA had struggled to give it any psychological meaning in the 1970s once its role as the kernel of psychological experience was rejected. However, Wing reaffirmed its significance by asserting its place within a 
general scale of social capacity. Instead of being an early psychic organiser, autism became a peripheral non-social experience, linked to other 'handicaps', which could be identified with tests and statistical tools and compared and contrasted with the otherwise rather boring standard results of the rest of the population. Autism no longer structured the psyche but it captured the imagination. It no longer channelled the social instincts but instead clarified them from above. The key feature of the shift in the meaning of autism in the 1970s and 1980s was the externalisation of developmental psychology. Meaning was suddenly shifted from internal theories to external testing schedules and mechanisms. Psychological knowledge about human relationships no longer had to be inferred from models of normal animal instincts but rather imposed from statistical knowledge about when it all went wrong. Developmental psychology organised and directed externally by the concept of autism, rather than merely employing the concept of autism as an infantile form of unconscious, hallucinatory, asocial mode of being. The concept of autism now began to drive psychology rather than vice versa.

Historically, there could have been no better time for such a shift. The population of children who would have previously been excluded from society on the grounds of their 'mental defect' were being fully acknowledged as social beings and fully integrated into the mainstream school system to develop along with all other children. It was no longer possible to conceptualise a model of society based on intellectual hierarchy where elite institutions housed the highest ranks and 'defective' institutions housed the lowest scorers of IQ tests. Psychologists trained at the Institute of Psychiatry were the first to conceptualise this new psychology because they helped to form the society in which it was created.

Between 1979 and 1981, Wing presented a critique of almost all previous classificatory systems and divisions drawn within child psychiatry and developmental psychopathology, including the work of Kanner, Heller, Mahler, de Sanctis and Van Krevelen. The classification of childhood disorders concerning social interaction was in 'a most unsatisfactory state', as she put it, because various 'syndromes' had been described without the full support of epidemiology or statistical methods. ${ }^{158}$ Wing then proposed to strip down descriptive psychopathology to its foundations in order to build it up again, brick by brick, around the concept of social impairment. Clearly, this was a wide 
and open goal because all conditions, issues, problem, etc. in children could arguably be regarded as forms of social impairment. Wing's work was thus, by proxy, a criticism of the whole field of child psychology and psychopathology. In fact, she argued that her theory concerning the 'triad of impairments' presented reasons to reconsider the psychological descriptions of 'schizoid personality', 'schizophrenia', 'other psychotic syndromes', 'obsessional neurosis' and 'affective conditions', thus appearing unconcerned, even nonchalant, about all other approaches to child and adult psychology that had preceded her own. ${ }^{159}$

Nevertheless, Wing was presenting an original argument, which was that all children's psychological conditions should be conceptualised in relation to their social capacities. It was not novel to suggest that children's social development was critical to understanding their psychological state; Susan Isaacs had argued as much. Nor was it novel to claim that children with 'impairments in social interaction' shared some similarities with children with intellectual impairments. What was new was that Wing and the new autism psychologists created new concepts and tools that could be used in the assessment of all children who were brought to the attention of social authorities. These concepts and tools were designed to replace theories of the unconscious. Not only did this satisfy the growing backlash against the kind of psychologists who blamed the mothers, but it also enabled a unifying of social scientific approaches to atypical or abnormal groups and naturalistic or genetic-based theories of such groups that had been widely criticised in the post-war era due to the taint of eugenics. Wing and the Maudsley psychologists created a way to overcome this because they placed psychological theory and social theory on a par. Wing's reason to focus on the problems of social interaction was that all the conditions in which the triad of language and social impairments occurs, whatever the level of severity, are accompanied by similar problems affecting social and intellectual skills. ${ }^{160}$ This was in many ways a tautology - of course impairments of social interaction affect social interaction - but it was a tautology that enabled a new science of psychology to develop. The metamorphosis of autism meant that tests for sensory impairment, perceptual problems and language disorder were reframed as problems of social interaction. A number of different kinds of impairment hence became 'social impairments'. The allure of this new science was due to the fact that it quantified domains of psychological knowledge 
that had previously been attributed to 'unconscious' mental processes that affected mental function. These were now reclassified as kinds of 'social impairment'. The new model of autism, the second autism, also provided a beautiful quantitative and statistical framework for everything that was unknown about children's thought about relationships. However, this did not obliterate the tautology. A social impairment is a social impairment.

In 1978, John Wing, Lorna Wing's husband, had published an edited volume showcasing Maudsley statistical and social scientific approaches to schizophrenia. ${ }^{161}$ Lorna Wing regarded these as a complement to her work as they highlighted the variability of schizophrenic symptoms across total population groups. Her own work sought to clarify this variability at a developmental level. Unlike Mildred Creak and other of her predecessors, Wing had freed herself from the chains of Piagetian developmental psychology.

In 1979, Wing and Gould published their study on the prevalence of what they termed 'Severe Impairment of Social Interaction and Associated Abnormalities' in children. They stated that the 'pattern of impairments and behaviour problems' that they were describing had previously been 'variously (and unfortunately) termed childhood psychosis, childhood autism, or childhood schizophrenia.' ${ }^{162}$ Wing and Gould essentially thought that these terms were unfortunate because they had divided the 'schizophrenic' child from the 'retarded' child. They argued that there were clear overlaps between autistic children and those who were administratively classed as 'subnormal', in particular those with IQs below 50. It was also noted that many children with 'abnormalities of social interaction and language development, and stereotyped behaviour' also performed as severely or mildly retarded on nonverbal tests. Wing and Gould therefore decided to scrap all previous definitions that had been made in relation to such children and to create their own classificatory system based on a prevalence study. The aim of Wing and Gould's 1979 study was to find: 'a) the prevalence and distribution of three types of abnormalities, and whether they tended to occur together, $b$ ) how the clinical pictures of which they formed a part could be subgrouped, and c) how they were related to mental retardation. ${ }^{163}$ Some 35,000 children under the age of fifteen were selected for the sample, gathered from the Camberwell Register, which had been established by the Social Psychiatry Research Unit in $1964 .{ }^{164}$ Using 
this register, Wing and Gould identified all children who were known to the local health, education or social services 'for reasons of physical or mental handicap or behaviour disturbance'; 914 children were selected, including those known to be 'severely mentally retarded'. The rest were screened via interviews to identify 'absence or impairment of social interaction', 'absence or impairment of development of verbal or non-verbal language' or 'repetitive, stereotyped activities of any kind'. These were taken directly from Rutter's three key features of autism. Some 132 children were selected in total. ${ }^{165}$

These 132 children were then given further tests. Previous schedules that had been specifically designed for 'retarded' children were thought to be unsuitable for the study because they 'do not cover in sufficient detail the development of ... comprehension and use of both verbal and nonverbal communication.' Likewise, 'checklists' for autism and childhood schizophrenia were considered unhelpful because they were 'far too selective to be useful with retarded but nonpsychotic children. ${ }^{166}$ What Wing and Gould created in their place was the Children's Handicaps, Behaviour and Skills (HBS) structured interview schedule - a system of measurement that would amalgamate both 'psychotic' and 'retarded' children, whilst at the same time enabling distinctions to be made according to their social abilities. In particular, they argued, their schedule was useful for distinguishing between autism and 'the specific developmental receptive and expressive speech disorders'. The schedule was described as 'a framework for eliciting, systematically, clinical information to be used in conjunction with appropriate, standardised psychological tests for assessment and diagnosis. ${ }^{167}$

The schedule enabled new distinctions to be drawn in the differentiation of children's psychological problems. Instead of dividing children purely by intellectual level, one could now divide them up by social level as well, as demonstrated in Figure 9. Furthermore, new subgroups could be created and these could be analysed by variables such as language comprehension, gender and age. Figure 10 shows a chart depicting methods used to differentiate socially impaired children, demonstrating, for example, that socially 'aloof' children were most likely to have a low level of language comprehension. This suggested that divisions according to social impairment fared just as well as the autism diagnosis when it came to statistically significant 


\begin{tabular}{lcc}
\hline & Socially impaired & $\begin{array}{c}\text { Sociable severely } \\
\text { retarded }\end{array}$ \\
\hline $\begin{array}{l}\text { Number of children } \\
\text { Percentages showing following } \\
\text { abnormalities }\end{array}$ & 74 & 58 \\
$\quad$ History of typical autism & $100)$ & $(100)$ \\
$\quad$ Speech & 23 & $0^{\mathrm{b}}$ \\
$\quad$ None & 55 & $33^{\mathrm{b}}$ \\
$\quad$ Echolalia & 35 & 17 \\
Idiosyncratic speech and/or reversal of & 8 & 0 \\
pronouns (ever) & & \\
Symbolic activities & 55 & $10^{\mathrm{b}}$ \\
$\quad$ None & 42 & 14 \\
$\quad$ Repetitive & & $7^{\mathrm{b}}$ \\
Overall interest pattern & 72 & 31 \\
$\quad$ Repetitive only & 28 & $0^{\mathrm{b}}$ \\
$\quad$ Repetitive and constructive & 23 & \\
Elaborate repetitive routines & & \\
\hline
\end{tabular}

\section{Notes}

a At time of interview unless otherwise specified

${ }^{\mathrm{b}} \mathrm{p}<.001$ (ch-square test)

Figure 9 Table distinguishing 'socially impaired' and 'sociable severely retarded' children, from Lorna Wing and Judith Gould, 'Severe impairments of social interaction and associated abnormalities in children:

Epidemiology and classification', Journal of Autism and Developmental Disorders 9, no. 1 (1979)

variables. The authors hypothesised that 'certain areas or functions of the brain are responsible for the development of social interaction and symbolic imaginative activities. ${ }^{168}$ They argued that some organic pathologies such as Down's syndrome left these functions intact but destroyed others. 'Social impairment' measures were the best way to conceptualise the mental problems of children because they were more closely related to known gross aetiology. In her radical critique of prior descriptions of autism, Wing argued that 'Mutism, echolalia, absence of or repetitive symbolic activities, and an interest pattern consisting entirely or partly of stereotyped activities did not differentiate those with and without a history of typical autism. On the other 
Comparison of methods of subgrouping socially impaired children: demographic, psychological and medical variables

\begin{tabular}{|c|c|c|c|c|c|}
\hline & \multicolumn{3}{|c|}{$\begin{array}{l}\text { Severity of social } \\
\text { impairment }\end{array}$} & \multicolumn{2}{|c|}{$\begin{array}{l}\text { History of typical } \\
\text { autism }\end{array}$} \\
\hline & $\begin{array}{c}1 \\
\text { Aloof }\end{array}$ & $\begin{array}{c}2 \\
\text { Passive }\end{array}$ & $\begin{array}{c}3 \\
\text { Odd }\end{array}$ & $\begin{array}{c}1 \\
\text { Present }\end{array}$ & $\begin{array}{c}2 \\
\text { Absent }\end{array}$ \\
\hline Number of children & 37 & 20 & 17 & 17 & 57 \\
\hline Rates per 10,000 aged $0-14$ years & 10.6 & 5.7 & 4.9 & 4.9 & 16.3 \\
\hline Percentages in each group & $(100)$ & $(100)$ & $(100)$ & $(100)$ & $(100)$ \\
\hline \multicolumn{6}{|l|}{ Chronological age at interview } \\
\hline$<10$ years & 46 & 30 & 53 & 64 & 54 \\
\hline $10+$ years & 54 & 70 & 47 & 36 & 46 \\
\hline \multicolumn{6}{|l|}{ Sex } \\
\hline Male & 70 & 80 & 71 & 94 & 67 \\
\hline Female & 30 & 20 & 29 & 6 & 33 \\
\hline \multicolumn{6}{|l|}{ Language comprehension age } \\
\hline$<20 \mathrm{~m}$ & 92 & 40 & $6^{\mathrm{a}}$ & 59 & 58 \\
\hline $20+\mathrm{m}$ & 8 & 60 & 94 & 41 & 42 \\
\hline \multicolumn{6}{|l|}{ Nonverbal IQ } \\
\hline $0-49$ & 78 & 40 & $53^{\mathrm{b}}$ & 35 & $70^{\mathrm{b}}$ \\
\hline $50-69$ & 17 & 25 & 35 & 35 & 19 \\
\hline $70+$ & 5 & 35 & 12 & 30 & 11 \\
\hline \multicolumn{6}{|l|}{ Reported age of onset } \\
\hline birth & 54 & 90 & $82^{\mathrm{c}}$ & 47 & $77^{\mathrm{b}}$ \\
\hline$<3$ years & 41 & 10 & 12 & 47 & 19 \\
\hline $3-5$ years & 5 & 0 & 6 & 6 & 4 \\
\hline \multicolumn{6}{|l|}{$\begin{array}{l}\text { Associated organic conditions } \\
\text { (hierarchical order) }\end{array}$} \\
\hline $\begin{array}{l}\text { Reported to be associated with } \\
\text { social, language and behavioral } \\
\text { impairment }\end{array}$ & 61 & 25 & $12^{\mathrm{a}}$ & 47 & 37 \\
\hline Down's syndrome & 3 & 0 & 0 & 0 & 2 \\
\hline Other identifiable conditions & 14 & 15 & 24 & 12 & 19 \\
\hline Dubious or none identified & 22 & 60 & 65 & 41 & 42 \\
\hline
\end{tabular}

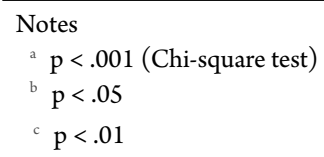

Figure 10 Table subgrouping socially impaired children, from Lorna Wing and Judith Gould, 'Severe impairments of social interaction and associated abnormalities in children: Epidemiology and classification', Journal of Autism and Developmental Disorders 9, no. 1 (1979) 
hand, they were very significantly associated with the degree of social impairment. ${ }^{\prime 69}$ In 1981, Wing explained her reasoning for grouping together children with the 'triad of impairments', she argued that

The justification for regarding them as related is that all the conditions in which the triad of language and social impairments occurs, whatever the level of severity, are accompanied by similar problems affecting social and intellectual skills. Furthermore, individuals with the triad of symptoms all require the same kind of structured, organized educational approach, although the aims and achievements of education will vary from minimal self-care up to a university degree, depending. ${ }^{170}$

Wing and Gould recommended that future studies of the mental problems of all children base their divisions upon social impairment as measured by the HBS. Impairments of reciprocal social interaction were reported to occur in 21.2 of every 10,000 children in the area studied, of whom 4.9 presented with a history of 'typical autism'. In all cases the symptoms had first been noticed before the child was five years old. ${ }^{171}$

Wing and Gould's attempt to place 'autistic' children on a continuum with other similar children was similar to Anthony's attempts to place 'severely psychotic' children on a continuum with other partially 'psychotic' children and they flagged up this connection. ${ }^{172}$ Whereas Anthony's three criteria had been based on psychoanalytic and Piagetian 'styles of reasoning' describing an 'a-genesis', 'a-cathexis' and 'a-dualism' in the process of development, leading to an inability to create a stable ego, 'displacement of affect onto things' and 'disturbances in the perception of the self', Wing and Gould described the problem purely in behavioural terms, creating their own triad of observable symptoms. ${ }^{173}$ In doing so, they transformed the problem of ego development and engagement with reality into a problem of social impairment and social adaptation. They also transformed the problem of sensory impairment into a problem of 'social impairment'.

What was innovative about Wing and Gould's 1979 study was that it fused the new sociological category of 'social impairment' along with prior classifications for autism and mental handicap. In doing this they generated a new model for uniting mental handicap and autism that fused the two into an epidemiological entity. Whereas Rutter, Tizard and Whitmore had, in the 1960s and early 1970s, employed the concept of 'social impairment' as a sociological measure in relation to an ability to function in society, Wing turned it into a psychological entity. 
Much has been made of Wing's article on 'Asperger's syndrome' in 1981 as it had such major repercussions. ${ }^{174}$ In short, Wing decided to employ a 1944 paper by the Austrian paediatrician, Hans Asperger, in order to support her own theories of autism and 'social impairment'. Although this story is often told as though Wing unearthed the true definition of autism in the historical past, in fact the reality surrounding Wing's recovery of the Asperger's paper is far more complex. Asperger's paper used very similar definitions of 'autism' and 'psychopathy' to those circulating amongst his contemporaries. What distinguished Asperger's paper was very similar to what distinguished Kanner's paper, namely that it contained very clear and concise case histories that contained vivid descriptions of individual children. Wing's 1979 article using statistical methodologies lacked this kind of description so Asperger's article was a useful tool for her. Furthermore, the Asperger's article supported her aims to break down the concepts of autism and schizophrenia and redefine them according to statistical models of social interaction. This was because Asperger's work highlighted the inconsistencies of the autism concept and its relation to schizophrenia. Wing's 'rediscovery' of Asperger's case studies were useful because they helped her to topple Kanner's hegemony concerning the concept of autism in childhood. They also enabled her to bring autism back this into the field of schizophrenia research, only to divide it up on new lines, unrelated to the concepts of hallucinations and delusions. She claimed that:

The relationship to schizophrenia of Asperger syndrome, autism and similar impairments can be reconsidered. Although they are dissimilar in family history, childhood development and clinical pictures, both groups of conditions affect language, social interaction and imaginative activities. The time of onset and the nature of the disturbances are different, but there are similarities in the eventual chronic defect states that either may produce. It is not surprising that autism and schizophrenia have, in the past, been confused. Progress has been made in separating them and it is important to continue to improve precision in diagnosis, despite the many difficulties met in clinical practice. ${ }^{175}$

As the mother of a child with the autism diagnosis in an unforgiving social climate, Asperger's male authority was also useful. It was via the Asperger's paper that Wing was able to support work on autism and social impairment that she had already outlined in 1979. 
Whereas sensory impairment, as described in the theories of Hermelin and O'Connor and Uta Frith in the 1960s, was very specific in its definition concerning a child's inability to 'sense' the external world through internal capacities, 'social impairment' expanded the limits of what could be conceived as coming under that title. More importantly, it reclaimed the study of human relationships as a science for the new psychology of autism, rather than a science for the Tavistock Institute of Human Relations and the instinct theorists. An infant's engagement with reality thus became synonymous with his or her engagement with social reality because the individual's engagement with social reality could be measured using epidemiology coupled with other methods from experimental psychology. By linking cognitive tests for autism, whether for pattern-detection or language abnormality, under the framing concept of 'social impairment', Wing brought them into the field of human relations psychology and gave them a new legitimacy within wider psychological theory. What more could one want to frame the psyche than the concept of society itself? There was no longer a need for the unconscious when all perceptual and sensory capacities were quantified, qualified and thoroughly known via statistical mapping. The parallels with the generation of evidence for the concept of intelligence in the early twentieth century are marked. With statistics and genetics, Maudsley psychologists sought to establish their model of learning and social development at the heart of British society. This was the basis for a new 'style of reasoning' about autism as a statistical and epidemiological entity.

The dominance of Tavistock models would change dramatically in the 1980s following Wing and Gould's tools to measure 'impairments in social interaction. Wing and Gould's work on 'social impairment' turned Maudsley autism psychology into a theory of human relationships. They thought that because the theory of human relationships was grounded in the theory of autism, their statistical and epidemiological models of autism would, by proxy, lead to new statistical and epidemiological models of human relationships and social development that were truly revolutionary. This would then complete the Maudsley critique of Tavistock models of psychological development. Wing and Gould even developed tests and tools to measure social impairment or the inability to engage or become a fully functioning social subject. Even Bowlby, with his ethological examples, and Winnicott, with his 
poignant descriptions of human development, had not conceived of the possibility of employing tests for social engagement in order to construct a theory of human relationships. It was through the development of such tests that Maudsley psychologists were eventually able to outshine the Tavistock generation in terms of guiding government policy and advising government officials on childcare and education.

The Newsons, with their sociological expertise, were critical to this transition. In the 1970s and early 1980s, government officials were informed about autism almost entirely by the work of Elizabeth Newson and Lorna Wing. George Young and other members of the DHSS had read a 1979 paper by Elizabeth Newson on 'Making Sense of Autism' that highlighted the point that an 'important, pervasive and intractable characteristic of the social impairment of autism is a failure to develop social empathy.'.176 She also drew attention to the flood of research in the late 1970 s that had focused on mother-baby interactions, demonstrating that the infant was far from passive in these interactions and that most 'babies are biologically and innately social, and are ready without being taught to play an active role in social interaction. ${ }^{177}$ Elizabeth Newson argued that in cases of autism, individuals lacked 'social empathy'. An autistic infant was 'suffering from a primary brain dysfunction which interfered with his ability to code or make sense of messages in all usual modalities - spoken language, gesture, facial expression and other body-language. ${ }^{178}$ This failure would 'effectively and repeatedly sabotage his earliest experience of social interaction. ${ }^{\text {'79 }}$ In this construction, the entire 'social' world, the ability to be 'social', became an entirely internal construction. This internal construction of the complete concept of 'the social' echoed legal changes made in relation to the workings of 'social services' at an externalist level. In other words, it was only possible to conceptualise a mental faculty or cognitive structure for 'the social' when it was possible to conceptualise an administrative service to cater to 'the social' from a political perspective. The Seebohm reforms thus also acted as the final juggernaut that stopped the growth of psychoanalytically inspired 'human relations' models of infantile thought.

Before the development of Wing and Gould's tests for social impairment and the Newsons' claims that babies were biologically and innately social, Institute of Psychiatry-trained psychologists had been limited in their ability to test for 'autism' or lack of social engagement. 
Lotter had given epidemiological data that could apparently quantify the problem. Hermelin, O'Connor and Frith had measured children's ability to code and understand the world through language and visual stimuli, but they were limited in their ability to explain social interaction, writ large. Rutter had developed tests to measure the exact impairment in language acquisition and unusual speech of autistic children. But no one had developed a test for social impairment in all its forms. In fact, many Maudsley and other cognitive psychologists in the 1960s and 1970s deliberately avoided all theories of 'failure of interpersonal communication' because they were actively seeking to demonstrate that psychosis and autism were caused by a brain-based cognitive impairment relating to sensory perception. This was precisely how Hermelin and O'Connor regarded the problem, and their theory was echoed in the USA by writers, such as Bernard Rimland, who argued that autistic children were unable to integrate separate experiences and relied on memory for problem-solving, rather than abstract thinking. ${ }^{180}$ Nevertheless, it was the Maudsley group who developed the tests to measure the precise cognitive problems of autistic children and it was this emphasis on measuring senses, perception, memory, recall, etc. that directed attention away from problems of human relationships. The Maudsley group also always employed statistical methodologies when analysing their results, thus providing clear quantitative evidence for the claims they were making about autistic specificity.

Whereas the first psychologists interested in social interaction and play, such as Isaacs and Lowenfeld, had derided both US attempts to measure social scales and behaviourism as a psychological approach, psychiatric epidemiology was a different beast. Behaviourists had argued that there was no way to measure human instincts whatsoever, that it was simply impossible and that therefore psychologists had to abandon their aim to explore these in their theories of socialisation. Psychiatric epidemiologists, on the other hand, did not disregard the theory of human instincts in psychology, but rather argued that epidemiological sciences had the potential to quantify and articulate drives towards social interaction. Once identified within total populations, social instincts and their vicissitudes could be tracked, mapped and understood, as could 'social impairments' or inabilities to create relationships and to socialise. In fact, in its own way, psychiatric 
epidemiology gave structure and scientific credibility to theories of natural or instinctive drives towards human interaction.

Anyone who presented a definition of autism that did not draw from psychiatric epidemiology in the 1970s and 1980s was widely criticised. For example, in the early 1970s, the Nobel Laureate Nikolas Tinbergen teamed up with his wife to develop an ethological theory of autism, building on the work of Bowlby. Their book Autistic Children: New Hope for a Cure argued that autism was caused by environmental stresses within the family, speculating that stressful situations caused by 'modern life' such as long car drives, high-rise tower blocks and parental neglect due to work pressures could all be 'autismogenic. ${ }^{181}$ Even though the Tinbergens put the word 'autism' in quotation marks, they clearly threatened cognitive and epidemiological scientists who were working with a model of autism that focused on recognising the impairments and disabilities of autistic people, and therefore helping to develop better education and social services for them. For the new cognitive autism researchers, the Tinbergen's pronouncements on the causative factors of 'modern life' were a joke. In a scathing review of the Tinbergens' book by Uta Frith, she argued that the Tinbergens' claims that modern life was damaging humanity was 'in a different class from that normally found in scientific discussions', that the authors failed to take into account the latest models of autism and that 'this book presents no more than a veneer of science.' ${ }^{182}$ This criticism of the scientific credentials of a Nobel prize winner must be viewed in context of the fact that the Maudsley model of autism, epidemiological autism, was supporting a new model of child disability rights. Tinbergen's science had therefore become politically problematic.

\section{Rethinking autism and children's rights in the 1980s}

Wing's model of 'social impairment' and children's rights provided the backbone to the implementation of social policies that integrated all children into the education system and society at large in the 1980s. The full integration of all children into the education system was a slow process. Although the 1970 Acts had ensured that all children were the responsibility of the education department, they did not provide any 
binding contracts that ensured that children with special educational needs actually progressed in their learning and social integration. It would take the Education Act 1981 (1983) to obligate LEAs to work with parents with the aim of ensuring progression.

The Education Act 1981 (1983) was based on the recommendations of the Warnock Report and it took seriously Rutter's studies on the prevalence of general handicap, as well as Pringle et al's National Child Development Study. ${ }^{183}$ Warnock's report had marked a watershed for the classification, research and 'special education' of children who were thought to be 'handicapped' physically or mentally, or both. The report had made it very clear that epidemiological and prevalence-rate studies issuing from the Institute of Psychiatry were much more reliable than previous counts for general psychological problems in children that had presented radically varying results. In 1977, one London borough had ascertained as 'maladjusted' ten times as many children compared with another London borough, thereby drawing attention to the inadequacy of that category when searching for statistical and administrative accuracy. ${ }^{184}$ However, Rutter's studies led Warnock and her colleagues to agree that 'the planning of services for children and young people should be based on the assumption that one in six children at any time and up to one in five children at some time during their career will require some form of special educational provision.' ${ }^{185}$ The plans under the Education Act 1981 (1983) were based on this measure.

Although the Warnock committee aimed to base service provision on prevalence-rate studies, they argued for specific individualised responses when addressing each particular child's problem. As they put it, 'the particular form presented by an individual child is not necessarily determined by the nature of any disability or disorder suffered by him. ${ }^{186}$ The committee then proposed that the term 'learning difficulties' should be applied to all children with any kind of special educational need and that all previous categories such as 'maladjusted' and 'educationally subnormal' should be abolished. The only thing that would now distinguish the groups from the perspective of education would be the 'specific' form of their problem, ${ }^{187}$ thus specific problems in learning became paramount to administrative definitions after 1983.

In the run-up to the 1981 Education Act (1983), the DHSS had raised questions about the identification of children with mental health problems prior to their entry into school. The Child Psychiatry Client 
Group of the Mental Health Advisory Committee then argued that 'screening for autism needed to be part of a wider screening system of pre-school surveillance with an emphasis on delayed language development' and that 'manpower planning for speech therapists should take account of the growing recognition of their value in the mental health field?. ${ }^{188}$ It was widely acknowledged that most child psychiatrists had very little understanding of the problem of autism, despite the fact that they were trained specialists in childhood mental health problems. This rather satirical situation was due to the fact that child psychiatrists had largely worked in child guidance clinics, which had not treated children with 'mental deficiency'. Professor Philip Graham, Consultant Advisor to the Chief Medical Officer, began discussions with the Institute of Psychiatry and the Institute of Child Health in the late 1970s concerning the establishment of relevant training in autism for child psychiatric professionals. ${ }^{189}$ The plan was that these institutions would lead others to take new approaches to autism in children, and challenge accounts that explored the play of these children within a framework of unconscious fantasy relations. ${ }^{190}$

The resulting report by the DHSS stated that the priorities of future health and social services for preschool children would be 'early identification and assessment', '[t] he development of home-based treatment plans' and 'the development, where appropriate, of specialised playgroup and day nursery facilities'. Using the language of Rutter and Wing, the report argued that 'autistic children, or children whose behaviour includes autistic features, need skilled help in a structured setting' to enable them 'to be helped to move away from the stereotyped "play" that may be inimical to their development.' The DHSS gave a grant to 'Family Tree' to develop home-based treatment programmes for preschool children. ${ }^{191}$ For school-age children, they recommended specialist input into schools and assessment facilities and the possible establishment of regional centres of specialist expertise. They also argued for better after-school care, although focused on those who came under the remit of 'services for the mentally handicapped'. ${ }^{192}$

For charitable groups dealing with the most complex cases of need, in particular the Society for Autistic Children, the generalisation of 'social services' only encouraged and impassioned them to argue that 'autistic' people were those who required the most attention to enable them to become social subjects. The Seebohm reforms had been 
criticised for the growth of bureaucracy and administrative paperwork that they had created, but also for the growing professionalism of social workers who may become more interested in career development than in helping needy people. The radical social work movement, 'Case Con', went further in claiming that the Act shifted blame onto families for their shortcomings, rather than acknowledging the role of the state in generating inequalities. ${ }^{193}$

These concerns about the need for greater understanding amongst general social workers to enable social adjustment came to a head in 1979. The Society for Autistic Children had made a deputation to the parliamentary secretary and a meeting was held on 5 October that brought together Sybil Elgar, Lorna Wing and other members of the SAC together with Sir George Young, junior health minister, and other members of the DHSS. The society argued that 'because social services departments had little experience of providing for autistic people', there was a strong need for training as there was 'a serious lack of social workers with the knowledge and experience to understand the autistic person' and that 'there were signs that social services departments might be becoming more reluctant to pay the necessary fees' for the establishment of specialist care for autistic children to live outside of the home. The society asked for greater education amongst health and social service authorities to ensure that they understood that 'the needs of autistic people were fundamentally different from those of the mentally handicapped generally' and to encourage social service departments to 'support voluntary effort' and enable local autistic societies to make use of closed hospitals and other buildings that the Seebohm reforms had made defunct. ${ }^{194}$ The Newsons also argued that people 'with autistic features' were clients with special needs for social services unlike no other client group because of their social impairments, and their views were repeated in government documents. ${ }^{195}$

In 1980, Young wrote to the Society for Autistic Children to say that he supported collaborations between NSAC and other local authorities, but remained lukewarm on the subject of further training workers to deal specifically with the needs of autistic people. There were, he argued, 'other groups of mentally handicapped people who have special needs or who suffer from syndromes which are not yet widely understood', and he could not give extra priority to autistic children, 
even though he would speak to other ministers about the possibility of disseminating information on the topic. ${ }^{196}$ In September 1979, one adviser, Vivienne Simmons, had been prepared to accept Lotter's figure of 4.5 per 10,000 with autism, but questioned the legitimacy of Wing's claims that the number of children with 'autistic features' was '2-3 times as many' as that, arguing in a prejudiced way that 'possibly her small Camberwell Sample with its high ethnic mix is atypical.' ${ }^{197}$ Another adviser, Mr French, argued that Wing's sample was definitely atypical and that all attempts to measure prevalence were 'sheer guesswork. ${ }^{198}$ However, this resistance to the growing application of autism within health and social service departments was countered by the increased interest in the education sector and, ultimately, in the passing of the 1981 Education Act (1983).

The 1981 Education Act, which became law on 1 April 1983, stated that all LEAs must draw up 'statements' that were legally binding contracts between the authority and the child's parents. ${ }^{199}$ In 1983, the DES and the DHSS issued a joint statement to all LEAs stating that in any description of a child's 'special educational needs':

The main focus should be on the child himself rather than on his disability. The extent to which a learning difficulty hinders a child's development depends not only on the nature and severity of that difficulty but also on the personal resources and attributes of the child, and on the help and support he receives at home and at school. ${ }^{200}$

Although this approach was ostensibly individualised, guidelines on completing the bureaucratic paraphernalia associated with the creation of 'statements' continually reiterated the point that the problems of 'statemented' children should be understood as 'strengths and weaknesses' in terms of their 'functioning. ${ }^{201}$ Such an approach echoed models of autism that highlighted a child's unique individuality as a function of their level of 'social impairment.' The Warnock Committee's proposal that a 'named person' should be responsible for supporting and informing the parents was not always followed in practice, and this resulted in varied liaisons between a multitude of professional groups directed only by these descriptive guidelines. ${ }^{202}$ Because of their promotion following the 1975 DES circular 2/75, educational psychologists increasingly took on the role of the 'named person' who represented the needs 
of the child concerned. They thus developed a vested interest in ensuring that a child received a statement.

An FA2 form was a legally binding statement under the Education Act 1981 in which a psychiatric professional described the special educational needs of an individual child. A typical FA2 form concerning a child diagnosed with autism in the 1980s read:

she showed repetitive and limited language, her social behaviours were very disinhibited, and she showed a great deal of attention-seeking behaviour, her imaginative play was limited and there was also some evidence of obsessional behaviours ... a school for children with mixed developmental disorders was, therefore, felt to be appropriate at this stage although it was noted that the placement would be reviewed regularly. ${ }^{203}$

Part of the goal of the Education Act 1981 was to further integrate children with special educational needs into mainstream schools. This process had already been set in motion after the 1970s and many separate units had been established within mainstream schools for the purpose of integrating 'handicapped' children. The number of 'handicapped' children receiving education in such units was counted as 11,027 in 1973 and this rose to 21,245 in 1977. ${ }^{204}$ The Education Act 1981 sought to increase the number of 'handicapped' children integrated into ordinary schools and encourage integration within schools themselves and not just in units on the school grounds. The Warnock Committee had described this as 'social' and 'functional' integration as opposed to integration purely in terms of location. ${ }^{205}$ This meant integrating handicapped children at social events such as eating and playing at lunch times and eventually involving them in 'functional' lessons in the classroom.

The introduction of the statementing system in 1983 increased the power and discretion of educational psychologists to make decisions concerning placement of children with 'autistic features'. In addition, because of the emphasis that the Act placed on integrating all types of children into normal schools, many children with 'autistic features' began to be integrated into mainstream classes. ${ }^{206}$ The appointment of home tutors to assist children with 'autistic features' in normal schools was a practice that began in 1983 and enabled children to get additional help at home that enabled their integration into mainstream education. 
In 1974, just thirty-four children registered with autism were being taught in special classes attached to mainstream schools, but after the Education Act was passed, children with 'autism' and 'autistic features' regularly began to be integrated into mainstream schools. ${ }^{207}$

It was via the Education Act 1981 that large numbers of professional groups were introduced to the term autism and also began to use it widely in the work of classifying and allocating children with diverse forms of 'special educational need. However, many of these professionals had not been trained to recognise the difference between a child who was hallucinating and one who was not, at least not through the traditional route of medical and psychiatric training, and this stirred the Royal College of Psychiatrists to try to claw back their exclusive rights to diagnose children. In fact, in 1988, the Royal College issued a statement to the DES and the DHSS criticising the implementation of the Education Act 1981 and claiming that the system was both slow and inexpedient. They then recommended that: 'Child and adolescent and where appropriate mental handicap psychiatrists should be involved with the placement of children whose special educational needs result from emotional or behavioural problems, including many children with intellectual and learning problems. ${ }^{208}$ Such children, they argued, constituted a 'high proportion of those who will be the subjects of statements of need' and that immediate steps be taken to consult psychiatrists directly concerning the placement of these children. However, this battle to regain psychiatric power over child classification was not won. Instead, through the operation of the statementing system, educational psychologists, parents, parent-led organisations, teachers, bureaucrats, administrators and psychiatrists had to work together to propagate and disseminate new categories. Autism had become the most salient of those categories because it referred to an individual state of mind that could be measured using psychiatric definitions and altered using educational means. The new autism psychologists' growing arsenal of testing equipment was used to outsmart psychoanalysts in their dominant discourse of human relations and interactions, and also to outwit IQ specialists and intelligence testers because it provided an alternative means to measure capacities and capabilities in children.

Although Tavistock models of human development had been very influential in policy relating to health and social welfare, an area in which human relations-style psychology did not gain a foothold in the 
post-war era was in the field of education. For the organisation of the schooling and education system, intelligence tests had provided far too strong and powerful a tool for political wrangling so that complex theories of social development and the unconscious in children took a back seat when it came to classroom planning. As Mathew Thomson has pointed out, older ideals and class divisions also guided government policies in this period. ${ }^{209}$ Education policy in the post-war period tended to focus on identifying and training or educating children according to a simply stratified vision of society. This changed radically following the Education Act 1981.

The strong support for the category of autism within the education system also had an effect on the organisation of wider social services, and encouraged parents to take a more active approach to their children's diagnoses. After the Education Act 1983, many parents began to request additional social service support specifically for the reason that their child had 'autism', claiming invalidity benefits and other forms of support such as mobility allowance and special allowances in the provision of housing. ${ }^{210}$ Again this introduced more professional groups working in social services to the subject of autism. This growing awareness of autism was coupled with increased attempts to identify it outside of educational circles.

In 1980, John and Elizabeth Newson launched a 'media search' for people with autism, requesting that journals and magazines help in getting in touch with the parents of 'autistic young people who may never have been diagnosed as such'. Newson specifically requested 'mildly autistic people', stating:

Some of your readers may have suspected that their child was autistic because from a very early age he was withdrawn, distant and aloof, and probably still remains 'cut off' socially in some ways. He is likely to have had certain obsessions and rituals, to have had odd difficulties in using and understanding language normally, and to use it now in a rather stilted and pedantic way. It will have been hard to have normal relaxed conversations with him because of this combination of social and language difficulties as well as obsessional preoccupations. ${ }^{211}$

The Newsons said that of autistic children of normal intelligence, it can be argued that these children suffer from the "purest" form of autism, in the sense that their handicap is not in terms of general 
mental retardation but in terms of the specific impairments that define autism. ${ }^{212}$ This interest in identifying and testing an expanding population of autistic individuals reflected the expansion of social services and educational services to cater to autistic groups.

Parents became acutely aware that the new autism psychologists could help them to gain the support that they wanted. For example, one mother wrote to the Newsons in the early 1980s in desperation after social workers had removed her child from her 'on grounds of her imputed neglect having "caused" the child's impairment. ${ }^{213}$ The Newsons brought in Lorna Wing to diagnose autism, and persuaded the director of social services for the local authority to return the child to her mother. For the Newsons, this only confirmed the need for further research on autism to prevent such injustices. Social workers needed better guidance when it came to making judgements about mothers and their capacities. This was no longer the era of the Tavistock theory of human relationships, the days were over of social workers making their own judgements about what caused children's problems. Parents began to reclaim their power to define what was or was not wrong with their children. They were coming to be increasingly supported under changes in childcare law.

Another important transition that took place in the 1980s was that the first generation of children given the autism diagnosis in the 1960s were now growing up and their needs were becoming increasingly apparent in legal discourse surrounding disability legislation. After the government acknowledged that all children had the right to an education, they also had to acknowledge that autistic adults also had to be integrated into the social fabric and supported. Responsibility for the social care needs of older individuals with autism had been debated since the 1970s. ${ }^{214}$ As autistic children grew into adulthood, many were referred on to government schemes introduced in 1975 and 1980 in order to improve their chances of living independently. ${ }^{215}$ In July 1983, G. P. Price, Project Development Officer for the Birmingham and District Society for Autistic Children, wrote a report on the special needs of autistic adults in the West Midlands that was forwarded to the then secretary of state, Mr Fowler. ${ }^{216}$ Price's report included an appendix by Lorna Wing explaining the triad of impairments. ${ }^{217}$ In 1984, Michael Rutter proposed to examine 'the specific socio-emotional deficits and abnormalities shown by autistic adults of normal non-verbal intelligence and a normal level of language expression and comprehension. ${ }^{218}$ 
In the early 1980s, John and Elizabeth Newson worked hard to highlight the fact that autistic children grew into autistic adults and that many of these adults developed new social needs. ${ }^{219}$ In 1984, a seminar was organised in collaboration with the DHSS. Newson estimated that 'autistic people with overall near-normal intellectual ability represent from 10-25 percent of the total autistic population', pointing out that this could be an underestimate because of the 'reluctance and failure of some professionals to recognise that autistic children are not necessarily mentally retarded' and the 'lack of agreement and clarity as to the definition of autism. ${ }^{220}$ The conclusion of the report was that better diagnostic services needed to be implemented and linked directly to follow-on advice. LEAs needed to improve their staff training, especially concerning 'the more able' children and educational provision needed to be considered in a number of settings. Newson criticised the focus on behaviour-modification techniques for autism, because she considered that they were aimed at the less able group. Newson also recommended 'interpersonal social skills training', particularly at adolescence, to inculcate social awareness, and that this training should continue beyond sixteen and possibly even nineteen years of age. Better vocational training and opportunities for sheltered state-organised employment should be offered. In the spirit of inclusivity and the new sociology, the Newsons even argued in the 1980s that autistic people should become part of the debate about their own needs and services.

It is clear that diagnoses of autism increased after the condition was related to mental deficiency, thereby expanding the category to include individuals who would previously have been excluded. What was equally important to the expansion of the category was the fact that age of onset was increased to cover the whole of childhood. This meant that 'social impairment' could be identified in older children with varying levels of intelligence. 'Autistic' became a description that could be used in multiple contexts covering multiple age ranges. From the perspective of welfare and social justice, this aimed to ensure that no one who could have benefited from a diagnosis lost out; however, it also meant that more infants, children and adults were regarded as suffering from a delay that affected their social, linguistic and imaginative capacities.

In the 1980s, local authority social service departments had to grapple with the fact that the 'social' world they were trying to manipulate was not a concept that everyone understood. At the 
same time, a theory was constructed that babies created 'the social' through innate cognitive mechanisms and not by instinctive desires for sexual and bodily relationships that they unconsciously fantasised about. It was during this transition that the creative aspects of play were rewritten not as attempts to imaginatively act out relationships, but rather as structured attempts to represent social scenarios, events and interactions.

\section{A new 'theory of mind'}

The changes occasioned by the Education Act 1981 were paralleled by new developments in the conceptualisation of autism within a general theory of psychology. As would be expected, the intellectual milieu that had been forged at the Institute of Psychiatry and University College London (UCL) was critical in shaping these new intellectual models or 'styles of reasoning. These theories would later become dominant internationally in shaping a general theory of autism. In 1982, Neil O'Connor retired from the UCL Medical Research Council Developmental Psychology Unit and it was taken over by John Morton, a graduate of Reading University and a member of scientific staff at the MRC Applied Psychology Unit in Cambridge. Morton renamed the unit the MRC Cognitive Development Unit and sought to focus attention on using experimental psychology to generate wider theories of general cognition. This was not something that had particularly interested Neil O'Connor but it would increasingly come to define the work of the unit. Under this new direction, Frith began to work on the subject of autism again and also began to supervise $\mathrm{PhD}$ students, most notably Simon Baron-Cohen. Frith, Baron-Cohen and Alan Leslie, a recent $\mathrm{PhD}$ graduate from the University of Oxford, became particularly interested in the potential for theories of autism to explain wider questions in general psychology.

In July 1983, Uta Frith started writing notes on the basic definition of autism, affirming to herself that Rutter's three criteria for autism were just a working definition of autism and 'there is still a need to relate cognitive/language/social/stereotypic phenomena in a meaningful way in order to explain varieties of autistic behaviour. ${ }^{221}$ In essence, this was also what Wing was working towards in her description of Asperger's syndrome. The fact that there were many varieties of autistic behaviour 
encouraged a wider conceptual model for the diagnosis. Frith's important contribution was to pose the question: 'How far are social difficulties part of [the] cognitive deficit?"222 In her notebook from 1983, Frith hypothesised that the 'cognitive dysfunction' of autism was due to a 'raw in-out cycle of processing', or 'processing without representation', where perceptual stimuli remain " "raw", "unanalysed", "not encoded". This short-circuiting of input and output was also the reason why some autistic people demonstrated very good motor skills, rote memory and drawing skills. Building on Hermelin and O'Connor's work, Frith reasoned that autistic people experienced all stimuli as of equal value; there was a lack of ability to embed 'hierarchically salient features' leading to 'excessive segmentation. ${ }^{223}$ It was this reasoning that led her to the hypothesis that autistic people had 'no intentionality, no "theory of mind", no person awareness, no social faculty."224 This therefore explained their 'lack of pretend play', 'inability to form and utilise symbols' and 'inability to communicate linguistically on a sophisticated level'. It meant that from the age of nine months to a year and onwards, autistic infants displayed an 'inability to take another person's mental state' and an 'inability to know ones own mental state.225

When Simon Baron-Cohen, Alan Leslie and Uta Frith argued that autistic children lacked a 'theory of mind' in 1985, they built on the post-1960s conception of autism, describing it as 'a profound disorder in understanding and coping with the social environment', in which the main symptom is 'impairment in verbal and non-verbal communication. ${ }^{226}$ Frith, Baron-Cohen and Leslie took the term 'theory of mind' from the work of Premack and Woodruff who had employed it to describe their study of chimpanzees. Frith, Baron-Cohen and Leslie used it to describe the ability to attribute autonomous mental states to the self and others so as to predict and explain actions. Leslie had been conducting work on the abilities of normal two-year-olds to understand pretend play and argued that autistic children showed deficits in their capacity for imagination. Baron-Cohen et al. then put forward the hypothesis that autistic children suffered an impairment in the cognitive mechanism required for 'mentalising' or representing mental states. 'False belief' tasks, in which subjects were tested to see if they could predict the thoughts of others, were employed to test this theory. In many trials, these tests were used to compare children with autism to control children with low language abilities or 
low IQ levels. ${ }^{227}$ These study designs were very similar to those used by Hermelin and O'Connor. The description of autism as a 'theory of mind' deficit did not exclude subjects who might have good vocabulary, syntax, phonology and rote language. Their only failure related to their ability to think of the mental states of others.

This attribution of autism as a 'theory of mind' deficit was the complete opposite of the theory of autism as a state of mind characterised by visual hallucinations and bodily experiences of relating to other objects and other people. It built directly on Wing's model of autism as a 'social impairment'. This theory of autism was only made possible by the integration of all child populations into a general theory of psychology and the subsequent removal of theories of adult psychopathology within developmental psychology. This was also related to the shift away from theories of instinctive motivations and 'maladjustment' that had prevailed within earlier models of child psychology. Interestingly, however, what was put in its place in the 1980s was: nothing. The theory of autism developed in this period stemmed from the claim that there was a complete absence of knowledge about the nature of early infantile thought and that only the conduct of more experimental psychology and epidemiological studies could fill this gap. This is how the theory of autism came not only to challenge but also to replace theories of unconscious instinctive motivations: because it broke down the psychoanalytic theory of ego development to its core, offering the potential to replace it with new, standardised, reproducible tests. The question of whether such tests could really explain the development of subjectivity within the context of the formation of relationships was a moot point. The new autism psychologists wanted to develop a new theory of mind.

Baron-Cohen, Frith and Leslie drew from Piaget's tests of 'egocentricity' in their proposition that autistic children lacked a 'theory of mind', in particular the test of 'three mountains' in which a child was asked to describe what could be seen from another person's point of view on a mountain. However, building on the work of Peter Hobson, they argued that the three mountains test only identified 'visuo-spatial skills', whereas their test could identify whether or not a child was able to impute 'higher-order' mental states to others. Children were presented with a model of a room with Sally, Anne, a basket, a box and a 
ball. They were told that Sally puts her ball in the basket and leaves the room. Whilst she is out, Anne takes the ball from the basket and puts it in the box. The question was: where would Sally look for her ball? Frith, Baron-Cohen and Leslie argued that those who are able to impute mental states to others would say that she would still think it is in the basket, whereas 'autistic' children will assume that she knows it is in the box.

This reformation of Piaget's famous test for egocentricity was particularly telling, as it was Piaget who had introduced the concept of autism into developmental psychology. For Piaget, autism existed before egocentricity and was not determined by it, but Frith, Baron-Cohen and Leslie argued that the Sally-Anne test was able to delve deep into a child's mental ability to understand other people's thoughts and that this was the explanation for all their problems. In fact, 'theory of mind' tests were a way to describe an individual's relationship to other minds that completely bypassed the thought processes that may have mediated that relationship. This model or 'style' of reasoning about autism represented exactly what was required in that historical moment - an account of the development of thought in infants that concerned their ability to relate to others, yet that did not speculate at all on the thought processes, hallucinatory or otherwise, that may have structured those relationships.

Although Wing had argued that autistic children lack 'symbolic representation' in 1976, she had not developed cognitive models to explain why this was, hence Frith's work, when collaborating with Baron-Cohen and Leslie, was important in forging new concepts. Thinking about the problem in relation to wider theories of child development, they reasoned that even in early infancy, humans show species-specific social behaviour in terms of 'interest in people, faces, voices', 'imitation', 'social smiling', 'early pointing' and 'anticipation of pick-up', and that therefore deficits in primary social responses may be indicative of autism. ${ }^{228} \mathrm{How}$ ever, what they needed to explain was the primary deficit and how this related to the second-order impairments. In their search for the basic perceptual problem of autism, Alan Leslie argued that this should be regarded not as a failure of selective attention but rather as an 'unusual "awareness" of lower level perceptual products.229 This drew from Hermelin and O'Connor's work on sensory awareness but was now, of course, framed in the language of cognition and information-processing. 
Frith, Baron-Cohen and Leslie knew that this presented a challenge to psychoanalytic models of development because it argued that social capacities, and the ability to think creatively and imaginatively, were not necessarily given psychological faculties. Whereas Isaacs, Klein and Anna Freud had built their theories on an edifice of human fantasies as the drives towards human relationships, Frith and colleagues were arguing that human relationships depended on an individual being able to adopt the perspective of another. Instead of the sex drive, it was the ability to see another's perspective that was the glue that created the social world. This was not just about how individuals diagnosed with autism were perceived, it was also about how society perceived its non-functional subjects. Instead of a social model built on reproduction and the exclusion of non-productive elements, Frith and colleagues espoused a social model built on 'social abilities' and the will to support and encourage those abilities. The Journal of Autism and Developmental Disorders continued to serve as a conduit for this new research on autism.

By the mid-1980s, the MRC Developmental Psychology Unit had around 800 babies on its books, whose mothers would bring them regularly by taxi to engage in studies of normal development. Work on autism had spurred the study of normal infantile perception, in an effort to understand the subtle differences that could cause that development to take an atypical route. Leslie became interested in testing infantile perceptions of cause and effect, employing increasingly sensitive tests to identify perceptions from very early ages, such as the way in which an eighteen-month-old would reach for an object with an anticipation of its weight, or the way that a six-month-old's visual attention would shift when it repeatedly watched collision events. He used these studies to demonstrate that even six-month-old infants could perceive cause and effect and that cause and effect was therefore built into the visual apparatus that an infant was born with. As with 'theory of mind' tests, these studies also sought to overturn Piagetian models of children's perception by presenting a model of children's thinking that could be tested and measured using proto-behavioural measures.

This also presented a challenge to Piaget's descriptions of cognitive development by demonstrating that typical children could understand cause and effect from a very early age, and that inabilities to reflect on the logic of certain situations could be due to inabilities to perceive the 
thought processes of others, rather than simple logical errors. As Leslie described the findings to a Nursery World reporter in 1985:

It would never have been dreamed of 20 years ago that a six-monthold could perceive cause and effect. It was originally thought that they would have difficulty in perceiving colours and even shapes. To find something as abstract and as sophisticated and intellectual as cause and effect amazed us and changed our whole view on how the human mind develops. ${ }^{230}$

New 'theory of mind' tests, together with the large-scale psychological investigation of babies' perception of cause and effect, proved a useful support to the epidemiological category of autism. There were, however, some major legal and social changes that had to occur before these theories and 'styles of reasoning' about children's social development, and autism as its antithesis, were adopted within mainstream theories of infant development.

\section{Autism and the Children Act 1989}

After the late 1970s, child psychology became increasingly framed around the second concept of autism and the logic of Wing's 'social impairment' model. It progressively applied and integrated the new sciences of measurable 'social impairment' into its theories of child development. Two things enabled this autification; first, the standardisation of testing schedules for autism, and second, the increased application of the category within the education system. Psychiatric epidemiology had given credence to the new autism and educational establishments grasped at these new certainties in their efforts to integrate diverse populations. Significant changes in the construction of children's rights over the course of the 1980s encouraged child psychologists to adopt the theory of autism as part of a political project of social integration. By supporting its logic of child autonomy and independence. Major changes in the construction of children's rights in British law affected how education, health and social service departments described children's individual differences. These changes in child law increasingly structured social services around an individual child's specific needs, rather than implementing them according to pre-formed ideas about family life and the services needed to protect it. The growth of tests to assess and 
measure autism and 'social impairment' fitted neatly into this new model of service provision for individuals, specifically children, with specific social needs. Once these legal transformations had taken place, increases in rates of autism began to be reported in epidemiological studies. These increases were largely a reflection of the fact that there were simply new ways to measure autism and that these new models had come to be accepted within the education system and across social services.

It was thus the administrative framework that supported the production of a new model of autism in Britain. The standardisation of autism under the wide umbrella of 'autistic spectrum disorders' and the way that schools and educational services readily adopted new psychological tests for autism in their efforts to integrate all kinds of children into mainstream educational settings in the 1980s helped to propagate this model. Psychological tests for autism have thus become critical to the formation of social policy relating to child welfare, health and education. 'Social deficit' models of autism have led psychologists, psychiatrists and even psychoanalysts to rethink their understanding of what is regarded as 'normal' social development. They have become standard fare in psychological textbooks, and part of the standard set of instruments used by educational psychologists and child health professionals. By tracing the development of these tests in relation to the increased prevalence of autism, one can see how the theory of autism has altered perceptions of parent-child relationships and has also transformed the organisation of educational and social services in Britain.

The mid-1980s saw radical attempts to restructure childcare and family law. In 1984, the Parliamentary Select Committee (Social Services Committee) was established to rationalise and modernise the law relating to children and families. It was conceded that the construction of childcare and child welfare law up until that point had been largely ad hoc and had arisen at different times regarding unrelated concerns. ${ }^{231}$ The committee concluded that 'social services', as they had come to be known generically under that title, were failing to work in partnership with parents and were too prone to rely on compulsory orders. This was largely a result of the Seebohm reforms, which had created standardised 'social service' departments as anonymous entities that were criticised for supporting their own existence rather than the needs of families. ${ }^{232}$ At the same time, organisations such as Justice for Children began organising themselves around the issue of children's rights and 
this approach was followed by specialist charitable organisations such as SAC, which was renamed the National Autistic Society in 1982. A 1985 report by the Department of Health, Review of Child Care Law, and the resulting white paper, The Law on Child Care and Family Services, argued for a 'major overhaul' of childcare law that resulted in the Children Act 1989 (1991).

The 1989 Act stated that all children, wherever possible, should be brought up within their own families and that if children had any specific needs relating to their welfare, these should be provided by external agencies that worked as service providers to the family. Children 'in need', as defined in the Chronically Sick and Disabled Person's Act 1970 and related legislation, including children diagnosed with 'autism', should be assessed and provided for in such a way as to minimise the effects of their disability and to enable them to lead 'lives which are as normal as possible."233

The 1988 Children Bill, which led to the Act, was described by the Lord Chancellor, Lord Mackay of Clashfern, as 'the most comprehensive and far-reaching reform of child care law which has come before parliament in living memory.234 One of the most striking changes occasioned by the Act was the introduction of rights for children to have a say in their own care. Children were thus no longer presented as the mere recipients of state and/or parental care but had a right to that care. As part of this transition, the concept of 'parental responsibility' superseded previous legal terminology that had described the 'rights', 'duties' or 'authority' of parents over their children. This moved away from the perception of the child as an object for the parents to own. As Clashfern put it: 'The overwhelming purpose of parenthood is the responsibility for caring for and raising the child to be a properly developed adult both physically and morally. ${ }^{235}$ At the same time, the Act also ensured that welfare professionals were also responsible for ensuring that children's rights were upheld. In fact, one of the major changes occasioned by the Act was the increased monitoring and accountability of welfare professionals in upholding those rights.

Prior to the passing of the 1989 Act, much child law had been phrased under the notion that children were defenceless creatures who needed the protection of social workers and other welfare agents who acted benevolently in the interests of the state. The 1989 Act overturned these ideas and gave agency to children as subjects in their own right. Children were reconceived as people to whom duties were owed, and were 
not just the possessions of others. Within the family courtroom, the Act ensured that 'the ascertainable wishes and feelings of the child concerned' be taken into account when decisions were being made about their care. ${ }^{236}$ Provisions were established to enable the easier presentation of children's views to the court. Local authorities were also made more accountable for decisions concerning children in their care, and complaints procedures were made available regarding decisions made about children in care or 'in need. ${ }^{237}$ Furthermore, local authorities were required to open and maintain a register of all disabled children in their area and this 'may be kept by means of a computer. ${ }^{\text {'238 }}$ Children were given powers of refusal to submit to medical or psychiatric examinations as directed by the court if they were deemed to have 'sufficient understanding' to make a refusal. ${ }^{239}$ The Act thus dealt a heavy blow to psychiatric authority. It gave new weight to children's own opinions and empowered them as individual subjects. The Act was very important in ensuring that children's individuality was recognised in law.

As well as leading major changes in disability and education legislation, parent groups such as SAC were part of a growing movement representing parental power to challenge decisions made by local authorities. These included Justice for Children, National Children's Bureau, Advisory Centre for Education, National Council for One Parent Families, and Voice of the Child in Care. ${ }^{240}$ In 1974, the Family Rights Group had been established to assist families involved with local authority intervention concerning their children's care. In 1979, the National Association for Mental Health (MIND), together with the Cobden Trust, published In Whose Best Interests?: The Unjust Treatment of Children in Courts and Institutions, a radical critique of then current practice for state assessment and provision for the needs of all children. This argued that in many cases where children had been placed in boarding schools for the 'Educationally Subnormal' (ESN), for example, 'it is no exaggeration to describe them as having been socially crippled by well intentioned and ill considered care' that had not equipped them with 'basic social survival skills. ${ }^{241}$ In Whose Best Interests advocated for a better legal framework to protect such children. In 1981, the Children's Legal Centre was established to advocate for children's rights. These publications and institutions led to the changes occasioned by the Children Act 1989. After the Children Act came into force in 1991, this new legal framework gave an important expression to children's desires, wishes, needs and wants, 
which had previously not been written into child law. It was this legal shift towards child autonomy that truly enabled the concept of 'autism' to become established and to grow and multiply as a dominant way of thinking about children's development and mental states.

Unlike earlier models, the 1980s model of autism offered certainty and clarity to government officials interested in developing new models of education and society based on neoliberal models of intervention that privatised public services and encouraged free-market competition. Margaret Thatcher, who famously declared in 1987 that 'there is no such thing as society', was then promoting these new visions as the prime minister. The statement was part of Thatcher's well-known rhetoric regarding the great value of the 'family' and the way that it should be protected from unnecessary state intervention. ${ }^{242}$ Her period as prime minister coincided with wider criticisms of state intervention and 'social services' through the formation of groups such as PAIN (Parents Against INjustice), which challenged the authority of 'social work' professionals to remove children from their parents. PAIN enlisted lawyers, doctors and others to support their cause, building new professional and legal networks working to challenge local authority decisions. ${ }^{243}$ These moves away from a model of children's rights that relied on benevolent local authority decisions were coupled with the move towards a model that relied on legal definitions of children's rights and 'social entrepreneur' parents who worked hard to ensure that these rights were met. From the viewpoint of psychologists from the Social Psychiatry Research Unit, 'social impairment' measures provided a way to measure each individual's potential to understand what society was. For Maudsley psychologists, 'society' needed to be reduced not just down to men, women and families, as in Thatcher and Hayek's vision, but into even smaller discrete entities that took account of each individual's unique abilities to engage in the social fabric. This was, in some ways, a form of individualism, but it took individualism to an extreme in its attempt to measure the very core of what individuality and social capacity were.

The 1980s thus saw a set of major shifts in the construction of child law that destabilised further the earlier discourse surrounding children's needs and development that were framed largely in the model of the Tavistock school of human relations. Institute of Psychiatry and UCL psychology researchers were at the forefront of these shifts. Lorna Wing petitioned education, health and social service departments to 
conceptualise children within a total population and then think about the limits of social abilities. Rutter, Tizard and Whitmore encouraged education authorities to develop the 'statementing' system to ensure that the needs of individual children were being met. The goal of both was to standardise children's experiences of society, to enable them all to live lives that were as 'normal' as possible. This vision fed into a new discourse of children's rights that ostensibly placed children at the centre of legislation concerning their health, education and welfare and encouraged inclusive social practices. Instead of supporting social hierarchies and class divides, this new model of society aimed to enable all children to develop to their potential. This new discourse of children's rights and the inclusion of children with all forms of 'handicap' obviously encouraged different visions of what constituted society at the level of government. However, it was also stimulating a reconceptualisation of the ways that individual children learned to become social beings. In other words, in the 1980s, it was not just Lorna Wing and the Maudsley-trained researchers who became interested in how far children could engage socially with others, respond to 'social services' and develop a broader appreciation of 'society'. Such questions were also being triggered in government and social work discourse by the changes occasioned by the recognition that children with mental handicaps or impairments had the right not only to an education, but to an education that was tracked and measured via legally binding documents. The idea that autism, or indeed any form of marked mental difference in childhood, was a kind of 'social impairment' slotted neatly into this new model.

There were some inherent contradictions in these changes. The Children Act reduced the powers of the state to intervene in family life, in the sense that it increased the accountability of welfare agencies and disallowed arbitrary state interventions. However, it also highlighted the need for children's individual freedom to be defended under the law, and to make sure that if and when the state did intervene in a child's care, it did so with the full weight of the law behind it. Thus, although children's autonomy and freedom were to be respected, this necessarily had to happen in a legalistic framework where procedures were clearly defined under the law. Child autonomy was granted, but it depended on its quality being constructed by legal agencies. Because of this, interest in the definition of child autonomy began to grow. People wanted to understand more about its nature, class, type and kind. 
Autism became a critical concept in the significant reframing of child law that occurred in the late 1980s. With a burgeoning interest in child autonomy, a growing number of professionals and parents became interested in psychological theories of social engagement and its absence. Although autism was increasingly defined as a 'social impairment' characterised by lack of imagination and of the ability to play, to communicate and to interact socially, this same model of autism was also used to affirm absolutely the rights of autistic individuals to participate in social life and to have their rights acknowledged and appreciated on a par with those without such impairments. It is this contradiction that has given autism its appeal as a diagnosis and as a way to challenge established psychological theory. This is why it has always been an 'enigma' to Uta Frith and others: it represents both the freedom and limitation of children's social expression and capacity.

The implementation of the Children's Act 1989 was a very complex process because interests, 'wishes and feelings' of children were always being weighed up in court against judgements about the child's 'best interests'. This put children's wishes on a whole new platform. Children's individual 'wishes and feelings' could clearly no longer be determined or classified by childcare professionals such as Susan Isaacs, John Bowlby or Margaret Lowenfeld, who claimed to have the authority to know what these really were. Now children's 'wishes and feelings' were important legal objects that had to be taken seriously in court. These defined a child's autonomy and their ability to state their needs. It should not be surprising that statistical psychologists such as Wing, Rutter, Tizard and Frith held much more legitimacy in their descriptions of child development than anyone who had focused only on children's desires as the measure of their identity. The Children's Act signalled a new vision of children's identity and freedom to state their wishes, and those wishes had to be legally verifiable. No wonder people began to take a much more cautious approach to the study of their expression. The full acceptance of statistically defined autism as a means to describe the individual thought patterns of children was one way that this Act was played out in children's new experiences of their personality, individuality and selfhood.

As the rights of individuals with mental atypicalities and differences were further supported in legal definitions, the new generation of epidemiological and experimental psychologists felt increasingly selfassured in their ability to make pronouncements on the significance of 
the autism category for understanding child development in general. The passionate support for the rights of children with serious difficulties in social interaction, and the campaigning for their rights on every level, necessarily had to be supported by further scientific investigations. In the 1980s, the concept of autism was, on one level, a key legal concept in the assurance of children's rights and, on another level, a central concept in the reframing of childhood psychological sciences as epidemiological and experimental sciences. The concept became increasingly entrenched on both of these levels, with child rights supporters and cognitive psychologists supporting each other in affirming the significance of autism and assuring services for any children diagnosed with the condition. By the late 1980s, the new autism psychologists had become stronger and more persuasive in their affirmation of their model of the category and its role in assuring rights to social care, education and acceptance for all. British researchers also persuaded the international community to adopt this approach.

The strength of conviction espoused by the Wings and the other new autism psychologists in Britain in the 1980s was impressive. They were very successful in advocating educational rights for autistic children in the UK, and in ensuring that a new network of agencies was established to support this project. This move towards the provision of services to children as part of a new market for care, rather than a top-down social intervention programme, slotted neatly into new neoliberal models of social welfare provision. The growth of autism and the growth of economic citizenship and advanced free-market liberalism thus went hand in hand.

However, when Lorna Wing's work and the science of autism epidemiology were launched on the global stage, they took on a life of their own and generated new ideas, thoughts and fears about the new autism. It is these international ideas about 'social impairment' and the new autism to which we will now turn.

\section{Notes}

1 Titmuss, Commitment to Welfare.

2 Seebohm, Report of the Committee on Local Authority and Allied Personal Social Services, p. 11. 
3 CLAAPS1968, p. 25; K. Jones, A History of the Mental Health Services, p. 332.

4 CLAAPS1968, p. 25; Mittler, 'Obituary: Stanley Segal'.

5 Brearley, Admission to Residential Care, pp. 69-84; Hendrick, Child Welfare: England 1872-1989, pp. 231-235; R. Harris, 'The life and death of the care order (criminal)'.

6 Roshier and Teff, Law and Society in England, p. 135.

7 Brearley, Admission to Residential Care, pp. 69-84.

8 Hansard: HC Deb 10 February 1971 vol 811 c 203W; CSDPA1970(1971).

9 Watkin, Documents on Health and Social Services 1834 to the Present Day, p. 108.

10 Thomas et al., The Health and Social Needs of Young Adults with Physical Disabilities, p. 99.

11 Robson and Kjønstad, Poverty and the Law, p. 82.

12 Hansard, 16 July 1970, vol 803, no. 14, col. 1684.

13 Hansard, 16 July 1970, vol 803, no. 14, col. 1691.

14 Bartak and Rutter, 'Special educational treatment of autistic children', 161.

15 Allison, 'Perspectives on a puzzle piece'.

16 K. Jones, A History of the Mental Health Services, p. 332.

17 DES figures quoted in Kushlik, 'Social problems of mental subnormality', p. 399.

18 K. Jones, A History of the Mental Health Services, pp. 353-365.

19 DES figures quoted in Ford et al., Special Education and Social Control, p. 24.

20 Ford et al., Special Education and Social Control, p. 24.

21 MHCP/A: 514794: Letter - Director of Education, Solihull, to Dr Skuse, November 1978.

$22 \mathrm{MHCP} / \mathrm{A}: 514794$.

$23 \mathrm{MHCP} / \mathrm{A}: 901137$.

24 MHCP/A: 723269.

$25 \mathrm{MHCP} / \mathrm{A}: 281589$.

$26 \mathrm{MHCP} / \mathrm{A}: 761794$.

$27 \mathrm{MHCP} / \mathrm{A}: 307194$.

28 NA/ED50/994: Branch meeting with HM inspectors, 30 March 1966, pp. 7-8.

29 Barkak and Rutter, 'Special educational treatment of autistic children', 165.

30 Rutter and Clark, 'Autistic Children's Responses', 216.

31 Allison, 'Perspectives on a puzzle piece', 6-9. 
32 Hurt, Outside the Mainstream, 182.

33 Kushlik, 'Social problems of mental subnormality', p. 399.

34 Summerfield Report, quoted in B. Harris, The Health of the Schoolchild, p. 210.

35 Department of Education and Science and Summerfield, Psychologists in Education Services.

$36 \mathrm{WT} / \mathrm{PSY} / \mathrm{BPS} / 1 / 4 / 2$ : British Psychological Society, minutes of the Committee on the Implications of the Summerfield Report, 1969-1971.

37 WT/PSY/BPS/1/4/2: First draft of Diploma in Developmental and Educational Psychology 1969; British Psychological Society, minutes of the Committee on the Implications of the Summerfield Report, 1969-1971, pp. 1-2.

$38 \mathrm{WT} / \mathrm{PSY} / \mathrm{BPS} / 1 / 4 / 2$ : First draft of Diploma in Developmental and Educational Psychology 1969; British Psychological Society, minutes of the Committee on the Implications of the Summerfield Report, 19691971 , p. 3.

39 WT/PSY/BPS/001/4/03: Fifteenth meeting, 16 February 1971, p. 2; British Psychological Society, minutes of the Committee on the Implications of the Summerfield Report, 1969-1971.

40 KCL/BCGC: Annual Reports, 1975 and 1976.

41 KCL/BCGC: Annual Report, 1976.

42 KCL/BCGC: Annual Report, 1976.

43 KCL/BCGC: Annual Report, 1979.

44 Harris, The Health of the Schoolchild, p. 182; Wooldridge, Measuring the Mind, p. 316.

45 Hansard, HC Deb 25 October 1983 vol. 47 c 132.

46 Lindsay, Screening for Children with Special Needs, pp. 88-89.

47 Hansard, HC Deb 13 November 1980 vol. 992 cc 421 w.

48 Hansard, HL Deb 28 July 1988 vol. 500 cc 386.

49 Rutter et al., Education, Health and Behaviour, p. 3. These types were modified when described from the child's perspective; pp. 348-351.

50 Rutter et al., Education, Health and Behaviour, p. 52.

51 Rutter et al., Education, Health and Behaviour, p. 292.

52 Rutter et al., Education, Health and Behaviour, p. 200.

53 Rutter et al., Education, Health and Behaviour, p. 108.

54 E.g. Berger et al., 'Attainment and adjustment in two geographical areas: II', 510. 
55 Rutter and Hersov, Child Psychiatry, p. 367.

56 WARNOCK1978, pp. 1-3.

57 Interview, Professor Sir Michael Rutter, conducted by Bonnie Evans, History and Philosophy of Science Dept, Cambridge, 7 December 2006.

58 WARNOCK1978, pp. 36-49.

59 Rutter et al., 'Attainment and adjustment in two geographical areas'; Berger et al., 'Attainment and adjustment in two geographical areas: II'.

60 Welshman, From Transmitted Deprivation to Social Exclusion.

61 Rutter et al., Education, Health and Behaviour.

62 WT/PP/ADD/E.5/2: Paper by Michael Power, MRC Social Medicine Research Unit, LSHTM, 26th Child Guidance Inter-clinic Conference.

63 J. K. Wing, 'Social treatments of mental illness', p. 27.

64 WT/PP/ADD/E.5/2: Paper by Mary Wilson, Staff Inspector for Special Education, ILEA, 26th Child Guidance Inter-clinic Conference.

65 WT/PP/ADD/E.5/2: Paper by Mary Wilson, Staff Inspector for Special Education, ILEA, 26th Child Guidance Inter-clinic Conference.

66 On the concept of 'deprivation' in the USA, see Raz, What's Wrong with the Poor?.

67 Ainsworth et al., Deprivation of Maternal Care.

68 Savage, Identities and Social Change in Britain since 1940.

69 Yudkin and Holme, Working Mothers and Their Children.

70 Yudkin and Yudkin, 'Poverty and child development'.

71 Schaffer and Emerson, 'The development of social attachments in infancy', 71.

72 Schaffer and Emerson, 'The development of social attachments in infancy', 71.

73 Brown and Rutter, 'The measurement of family activities and relationships'.

74 Rutter, Maternal Deprivation Reassessed.

75 Rutter, 'Maternal-deprivation, 1972-1978'.

76 Wolkind and Rutter, 'Children who have been "in care".

77 National Archives: MH166/1503: Research proposal by John and Elizabeth Newson in association with Peggie Everard (formerly Hon. Secretary NSAC), p. 1.

78 Kanner, 'Childhood psychosis', 2.

79 Kanner, 'Childhood psychosis', 19.

80 Rutter and Bartak, 'Causes of infantile autism', 29.

81 Rutter and Bartak, 'Causes of infantile autism', 27. 
82 Richards, Putting Psychology in Its Place, p. 91.

83 Hayward, 'The tortoise and the love-machine.'

84 Gardner, The Mind's New Science, pp. 32-33; G. Richards, Putting Psychology in Its Place, p. 94.

85 Gardner, The Mind's New Science, pp. 191-193; Chomsky, 'A review of B. F. Skinner's Verbal Behaviour', p. 563.

86 Chomsky, 'A review of B. F. Skinner's Verbal Behaviour', pp. 578, 563.

87 Chomsky, 'A transformational approach to syntax', pp. 182-191; Gardner, The Mind's New Science.

88 E.g. Mittler, 'Opening remarks', p. 142; Howling, 'The effectiveness of operant language training', 101.

89 Central Advisory Council for Education, Children and Their Primary Schools.

90 Piaget, 'The psychogenesis of knowledge', p. 23.

91 Piaget, 'The psychogenesis of knowledge ', p. 31.

92 Piaget, 'The psychogenesis of knowledge', p. 59.

93 Rutter, 'Speech disorders in a series of autistic children', p. 45.

94 Rutter, 'Behavioural and cognitive characteristics'.

95 Rutter, 'Concepts of autism', 12.

96 Rutter et al., 'A comparative study of infantile autism: I', 127.

97 Rutter et al., 'A comparative study of infantile autism: I'; Bartak et al., 'A comparative study of infantile autism: III'.

98 Rutter et al., 'A comparative study of infantile autism: I'; Bartak et al., 'A comparative study of infantile autism: III'.

99 Bartolucci et al., 'Phonological investigation of verbal autistic and mentally retarded subjects', 303.

100 E.g. Rorty, The Linguistic Turn; Clark, History, Theory, Text.

101 Morley, The Development and Disorders of Speech in Childhood; Schofield, 'Morley, Muriel Elizabeth (1899-1993)'.

102 See Clarke and Jacyna, Nineteenth-Century Origins of Neuroscientific Concepts; Harrington, Medicine, Mind and the Double Brain; Young, Mind, Brain and Adaptation in the Nineteenth Century.

103 Head, Aphasia and Kindred Disorders of Speech.

104 Orton, Reading, Writing and Speech Problems in Children, p. 2; Brain, 'Speech and handedness'.

105 Ingram, 'Specific developmental disorders of speech in childhood', 450.

106 Franklin, Children with Communication Problems.

107 Eyal et al., The Autism Matrix, p. 197. 
108 Bax and Whitmore, 'Neurodevelopmental screening in the schoolentrant medical examination.

109 Drillien and Drummond, Neurodevelopmental Problems in Early Childhood.

110 L. Wing, 'A place in life'.

111 E.g. $\mathrm{MHCP} / \mathrm{A}: 909969$.

112 MHCP/A: 603491: Letter from Dr Michael Black, Consultant Psychiatrist Bedfordshire County Council CGC, 13/6/69; NA/ED50/ 969: Report on Ealing School, 1968.

113 McCarthy and Kirk, Illinois Test of Psycholinguistic Abilities; Danforth, The Incomplete Child.

114 MHCP/A: 200150: 'Assessment of intelligence in an autistic boy', 8/1/73.

115 MHCP/A: 533358: Letter - Martin to Rutter, November 1969.

116 MHCP/A: 533358: Letter - Martin to Rutter, November 1969.

117 MHCP/A: 726323: Report, October 1979.

118 MHCP/A: 275685: Summary, February 1974.

119 MHCP/A: 856229: Formulation, October 1982.

120 MHCP/A: 470433: School report, February 1978.

121 MHCP/A: 397168: Report, June 1975.

$122 \mathrm{MHCP} / \mathrm{A}: 143950$ : Letter to Rutter, 1970.

123 MHCP/A: 143950: Letter from Rutter, 1970.

$124 \mathrm{MHCP} / \mathrm{A}: 1970$ s cases.

125 Rutter, 'Concepts of autism', 4.

126 Rutter, 'Concepts of autism', 4.

127 MHCP/A: 196002: Letter from Weiselberg, 31/6/75(1).

128 MHCP/A: 196002: Letters from Weiselberg, 31/6/75(2), 31/6/75(3), $8 / 7 / 75$.

$129 \mathrm{MHCP} / \mathrm{A}: 260422$.

130 MHCP/A: 430794: Letter from Rutter, 27/12/78.

131 MHCP/A: 430794: Letter from Rutter, 27/12/78.

132 E.g. MHCP/A: 982784. Letter from Rutter, 15/10/75.

$133 \mathrm{MHCP} / \mathrm{A}: 603491$.

$134 \mathrm{MHCP} / \mathrm{A}: 172559$.

135 Schopler et al., 'Editorial: Change of journal scope and title'.

136 Anon., 'Advertisement: Journal of Autism and Childhood Schizophrenia'.

137 National Archives: MH166/1503: Mental Illness Working Group RLG, 12 July 1978.

138 Piaget et al., The Psychology of the Child. 
139 Newson and Newson, 'Intersubjectivity and the transmission of culture', 438.

140 Newson and Newson, 'Intersubjectivity and the transmission of culture', 438 (emphasis added).

141 Trevarthen et al., 'Psychological actions in early infancy'.

142 Condon and Sander, 'Synchrony demonstrated between movements'; Condon and Sander, 'Neonate movement is synchronized with adult speech'. Woolf, 1969.

143 Trevarthen and Hubley, 'Sharing a task in infancy', 72.

144 Husserl, Cartesian Meditations, 5th Meditation.

145 Merleau-Ponty, Phénoménologie de la perception, p. 404.

146 Habermas, 'Towards a theory of communicative competence'.

147 Trevarthen, 'Communication and cooperation in early infancy'; Trevarthen and Hubley, 'Secondary intersubjectivity'.

148 Newson and Newson, 'Intersubjectivity and the transmission of culture', 445.

149 Hobson, 'Early-childhood autism and the question of egocentrism'.

150 Ricks and Wing, 'Language, communication, and use of symbols'.

151 L. Wing et al., 'Symbolic play in severely mentally-retarded and in autistic-children', 169.

152 L. Wing et al., 'Symbolic play in severely mentally-retarded and in autisticchildren', 173.

153 Hermelin, 'Images and language', p. 141.

154 Hermelin, 'Images and language.'

155 L. Wing, 'Perceptual and language development in autistic children'.

156 L. Wing, 'Perceptual and language development in autistic children', pp. 188-189.

157 Wing and Gould, 'Severe impairments', 12.

158 L. Wing, 'Asperger's syndrome', 121-122.

159 L. Wing, 'Asperger's syndrome', 124.

160 J. K. Wing, Schizophrenia.

161 Wing and Gould, 'Severe impairments', 11.

162 Wing and Gould, 'Severe impairments', 13.

163 Wing and Gould, 'Severe impairments'.

164 Wing and Hailey, Evaluating a Community Psychiatric Service.

165 Wing and Gould, 'Systematic recording of behaviours and skills', $80-81$. 
166 Wing and Gould, 'Severe impairments', 26.

167 Wing and Gould, 'Severe impairments', 22.

168 L. Wing, 'Asperger's syndrome', 124.

169 Wing and Gould, 'Severe impairments', 26.

170 Wing and Gould, 'Severe impairments', 26.

171 Wing and Gould, 'Severe impairments', 12.

172 Wing and Gould, 'Severe impairments'.

173 L. Wing, 'Asperger's syndrome', 124.

174 NA/MH154/1521: 'Making Sense of Autism' by Elizabeth Newson, p. 8.

175 NA/MH154/1521: 'Making Sense of Autism' by Elizabeth Newson, p. 21 (emphasis in original).

176 NA/MH154/1521: 'Making Sense of Autism' by Elizabeth Newson, pp. 21-22.

177 NA/MH154/1521: 'Making Sense of Autism' by Elizabeth Newson, p. 22.

178 Silberman and Feinstein.

179 L. Wing et al., 'The prevalence of early childhood autism'; Wing and Gould, 'Severe impairments', 80.

180 Rimland, Infantile Autism.

181 Tinbergen and Tinbergen, Early Childhood Autism.

182 Frith, 'Review of Tinbergen, Autistic-children: New hope for cure', 461, 463.

183 Kellmer-Pringle, 11,000 Seven-Year Olds.

184 WARNOCK1978, para. 3.7.

185 WARNOCK1978, para. 3.17. One-in-six figure was taken from Rutter et al., Education, Health and Behaviour, p. 348.

186 WARNOCK1978, para. 3.21.

187 WARNOCK1978, para. 3.26.

188 NA/MH154/1521: Meeting to discuss policy on autism 23 August 1978, pp. 1-3.

189 NA/ MH154/1521: Draft 'Policy on Autism', 5 December 1979, p. 5.

190 NA/ MH154/1521: Brief for meeting between Parliamentary Secretary (HPSS) and NSAC, 5 October 1979.

191 NA/MH166/1504: 'Policy on Autism' report, December 1979.

192 NA/MH166/1504: 'Policy on Autism' report, December 1979.

193 Turbett, Doing Radical Social Work. 
194 NA/MH154/1521: Note of a meeting with the NSAC, 5 October 1979.

195 National Development Group for the Mentally Handicapped, Improving the Quality of Services for Mentally Handicapped People, p. 33, para 75.4.

196 NA/MH154/1521: Note from George Young to the Society for Autistic Children, 1980.

197 NA/MH154/1521: Dr Vivienne Simmons, Comments on meeting between PS and NSAC, 26 September 1979.

198 NA/MH154/1521: Note by Mr French.

199 KCL/BCGC: Annual Report 1983.

200 MHCP/A: 590494: DHSS/DES circular 1983, quoted in ILEA notes on Education Act 1983, Appendix 3.

201 MHCP/A: 590494: DHSS/DES circular, 1983.

202 KCL/BCGC: Annual Report, 1983.

203 MHCP/A: 590494: ILEA Special Educational Needs form FA2, March 1985.

204 WARNOCK1978, para 7.2.

205 WARNOCK1978, para 7.7-7.9.

$206 \mathrm{MHCP} / \mathrm{A}: 497583$.

207 Hansard, HC Deb 20 December 1974 vol. 883 cc 627W; e.g. MHCP/ A: 901137; Hansard, HC Deb 27 January 1988 vol. 126 c 233W.

208 Royal College of Psychiatrists, 'Statement to the DES and DHSS', 72.

209 Thomson, Lost Freedom.

210 E.g. MHCP/A 659400; 865920; 917644; 755419; 133378.

211 NA/MH166/1504: Letter from Elizabeth Newson to Dr Dastgir, Department of Health and Social Security, 30 September 1981. Attached note A.

212 NA/MH166/1503: Research proposal by John and Elizabeth Newson in association with Peggie Everard (formerly Hon. Secretary NSAC), p. 2.

213 NA/MH166/1504: Letter from Elizabeth Newson to Dr Dastgir, Department of Health and Social Security, 30 September 1981.

214 Letter from C. H. Benson to Mr Straubenzee 1971, National Archives: 'Extended Education for Autistic Children Beyond the Age of 16' (ED 269/62).

215 White Paper quoted in Malin, Services for the Mentally Handicapped in Britain, pp. 112-115; Fiddy, In Place of Work, pp. 1-2. 
216 NA/MH166/1504 DHSS: Letter from C. L. Souter, private secretary to Mr Fowler, to G. P. Price; NA/MH166/1504: Report by G. P. Price on the West Midlands, 1983.

217 NA/MH166/1504: Wing, 'The handicaps of autistic children', Appen$\operatorname{dix} 3$ to G. P. Price Report.

$218 \mathrm{MHCP} / \mathrm{A}$ : Rutter's files: 'Some notes on the naturalistic study of social interactions of intellectually able autistic adults', 26/6/84.

219 NA/MH166/1504: 'Note of client group to discuss seminar on autism'.

220 NA/MH166/1504: E. Newson et al., 'Summary of report to the DHSS', p. 1; E. Newson, 'Diagnosis and early problems of autistic children'.

221 RSA Uta Frith Archive: Uta Frith, Notebook: History of Ideas Autism, 1968, 1970, 1983-1984. 'Basic Diagnosis: 7.7.83', p. 1.

222 RSA Uta Frith Archive: Uta Frith, Notebook: History of Ideas Autism, 1968, 1970, 1983-1984. 'Basic Diagnosis: 7.7.83', p. 1.

223 RSA Uta Frith Archive: Uta Frith, Notebook: History of Ideas Autism, 1968, 1970, 1983-1984. 'Basic Diagnosis: 7.7.83', p. 7.

224 RSA Uta Frith Archive: Uta Frith, Notebook: History of Ideas Autism, 1968, 1970, 1983-1984. 'Basic Diagnosis: 7.7.83', p. 8.

225 RSA Uta Frith Archive: Uta Frith, Notebook: History of Ideas Autism, 1968, 1970, 1983-1984. 'Basic Diagnosis: cont. 15.10.84', p. 8.

226 Baron-Cohen et al., 'Does the autistic child have a "theory of mind"?'.

227 Leslie and Frith, 'Autistic children's understanding'; Perner et al., 'Exploration of the autistic child's theory of mind'.

228 RSA Uta Frith Archive: Uta Frith, Notebook: History of Ideas Autism, 1968, 1970, 1983-1984, 'Primary social responses versus higher order social responses 12.09.84-12.10.84', p. 21.

229 RSA Uta Frith Archive: Uta Frith, Notebook: History of Ideas Autism, 1968, 1970, 1983-1984. 'Primary social responses versus higher order social responses 15.10 .84 ', p. 23.

230 Robinson, 'People talk with their eyes'.

231 Parton and Lyon, 'Children's rights and the Children Act 1989'.

232 Pilcher and Wagg, 'Keeping it in the family'.

233 Children Act 1989, Schedule 2, Part 1, para 6.

234 Hansard, HL Deb 6 December 1988 vol. 502 cc 488.

235 Hansard, HL Deb 6 December 1988 vol. 502 cc 490. 
236 CA1989 (1991), Sched. 2, Part 1, para 2.

237 CA1989 (1991), Part 1, Section 1(3)a.

238 CA1989 (1991), Sched. 2, Part 1, para 2.

239 Parton and Lyon, 'Children's rights and the Children Act 1989'.

240 L. Taylor et al., In Whose Best Interests?, p. 94.

241 Taylor et al., In Whose Best Interests?, pp. 58-59.

242 Pilcher and Wagg, Thatcher's Children, p. 2.

243 Crane, 'Painful times'. 